University of Nebraska - Lincoln

DigitalCommons@University of Nebraska - Lincoln

Publications from USDA-ARS / UNL Faculty

U.S. Department of Agriculture: Agricultural

Research Service, Lincoln, Nebraska

2005

Measurement of Soil Respiration in situ: Chamber Techniques

Philippe Rochette

Agriculture and Agri-Food Canada

Gordon L. Hutchinson

USDA-ARS

Follow this and additional works at: https://digitalcommons.unl.edu/usdaarsfacpub

Rochette, Philippe and Hutchinson, Gordon L., "Measurement of Soil Respiration in situ: Chamber Techniques" (2005). Publications from USDA-ARS / UNL Faculty. 1379.

https://digitalcommons.unl.edu/usdaarsfacpub/1379

This Article is brought to you for free and open access by the U.S. Department of Agriculture: Agricultural Research Service, Lincoln, Nebraska at DigitalCommons@University of Nebraska - Lincoln. It has been accepted for inclusion in Publications from USDA-ARS / UNL Faculty by an authorized administrator of DigitalCommons@University of Nebraska - Lincoln. 


\title{
Measurement of Soil Respiration in situ: Chamber Techniques
}

\author{
PHILIPPE ROCHETTE \\ Agriculture and Agri-Food Canada \\ Sainte-Foy, Québec, Canada \\ GORDON L. HUTCHINSON \\ USDA-ARS \\ Fort Collins, Colorado
}

Soil respiration is commonly estimated as the flux of $\mathrm{CO}_{2}$ emitted from the soil surface $\left(F_{\mathrm{c}}\right)$. It represents the sum of $\mathrm{CO}_{2}$ produced by root respiration and by heterotrophic decomposition of root exudates, soil organic matter, and plant litter. The influence of $\mathrm{CO}_{2}$ fixation by autotrophic soil microorganisms, as well as nonbiological reactions such as the chemical oxidation of organic molecules and the precipitation or dissolution of soil carbonates, is small in most situations (Suarez, 1999). Root respiration is largely regulated by the root biomass and the rate of photosynthate transfer from plant leaves and often exhibits a strong diurnal pattern. It may represent 10 to $90 \%$ of soil respiration (Hanson et al., 2000). Decomposition processes are the result of complex interactions among soil fauna, fungi, actinomycetes, and bacteria. The organisms break down complex molecules such as cellulose, hemi-cellulose, proteins and lignin into low-molecular-weight substances, which are then oxidized to $\mathrm{CO}_{2}$ to produce energy or used to provide $\mathrm{C}$ for cell growth. The rate of decomposition is determined by the quantity and quality of organic substrates, the efficiency and population dynamics of various decomposer groups, and the soil's physico-chemical environment including moisture, temperature, oxygen, acidity, and redox potential (Kilham, 1994; Coleman \& Crossley, 1996).

Soil respiration is considered a good estimator of overall biological activity and has been proposed as a descriptor of soil quality (Doran \& Parkin, 1994). Soil respiration measurements are increasingly used in studies of soil C cycling to detect early changes in decomposition rate of soil organic matter in response to various soil or crop management practices (Jensen et al., 1996; Rochette \& Angers, 1999). The soil respiration rate also must be known to estimate net crop photosynthesis from net ecosystem $\mathrm{CO}_{2}$ exchange (Rochette et al., 1995) and finally, most approaches proposed for measuring root respiration in situ include measurements of soil-surface $\mathrm{CO}_{2}$ emissions (Hanson et al., 2000).

Chamber techniques have been used to estimate soil respiration for more than eight decades (Bornemann, 1920) and remain the most commonly used

Copyright @2005. American Society of Agronomy, Crop Science Society of America, Soil Science Society of America, 677 S. Segoe Rd., Madison, WI 53711, USA. Micrometeorology in Agricultural Systems, Agronomy Monograph no. 47. 
approach. They permit measurement of very small $F_{c}$, are relatively inexpensive to build and use, and can be adapted to a wide range of field conditions and experimental objectives. Several reviews of chamber techniques for soil-surface gas flux measurements have been published recently (e.g., Livingston \& Hutchinson, 1995; Holland et al., 1999; Hutchinson \& Livingston, 2002), but few of these have been specific to soil respiration. While many aspects of flux measurement methodology are common to a large group of relatively non-reactive gases, each gas has some particularities. For example, $\mathrm{CO}_{2}$ fluxes have been and are still being measured with chambers using chemical traps for absorbing emitted $\mathrm{CO}_{2}$. Since publication of the last review on soil respiration (Nakayama, 1990) the introduction of rugged, sensitive, portable $\mathrm{CO}_{2}$ analyzers has revolutionized chamber technology for determining surface $\mathrm{CO}_{2}$ flux and has led to the development of commercial soil respiration measurement systems.

Regardless of which type of chamber is used, its placement on the soil surface perturbs natural conditions and can modify the flux it was intended to measure. In this chapter, we describe the physical and biological factors affected by chamber deployment and discuss ways to minimize the impact of those changes on chamber determination of $F_{\mathrm{c}}$. We also discuss the principles of operation of steady-state and non-steady-state chambers, as well as the methodology for spatial and temporal integration of chamber measurements.

\section{FACTORS INFLUENCING CHAMBER PERFORMANCE}

Because chamber methods depend exclusively on headspace gas concentration measurements or determining the unused capacity of a known chemical trap, they provide only an indirect measure of the $\mathrm{CO}_{2}$ flux across the soil surface, which is in turn equal to the soil respiration rate only under steady-state conditions. Thus, the challenge when using chamber techniques is to minimize perturbations by the chamber of not only the underlying rates of root and microbial respiration, but also the transport and emission phenomena that determine what fraction of total $\mathrm{CO}_{2}$ production reaches the headspace of the chamber during its period of deployment. The principal factors influencing chamber performance include soil and air temperature, $\mathrm{CO}_{2}$ concentration gradients, pressure fluctuations, soil and air moisture, site disturbance, leakage, and air mixing regime.

\section{Soil Temperature}

Soil respiration approximately doubles for every $10^{\circ} \mathrm{C}$ rise in soil temperature $\left(T_{\mathrm{s}}\right)$ between 5 and $30^{\circ} \mathrm{C}\left(Q_{10}=2\right)$ and decreases sharply above $40^{\circ} \mathrm{C}$. When $Q_{10}=2$, a change of $1^{\circ} \mathrm{C}$ in $T_{\mathrm{s}}$ results in a $7 \%$ change in respiration rate. Because most respiration activity occurs in the top $25 \mathrm{~cm}$ of soil, it is obvious that chamber techniques must minimize changes in near-surface soil temperature during deployment. There is surprisingly little information in existing literature regarding the impact of chambers on soil temperature. Sharkov (1984) reported that the daytime difference in $T_{\mathrm{s}}\left(\Delta T_{\mathrm{s}}\right)$ at $10-\mathrm{cm}$ depth between the inside and outside of a thin-wall duralumin chamber was +0.5 to $+1.5^{\circ} \mathrm{C}$ during clear days. The differ- 
ence in mean daily values was smaller $\left(+0.5^{\circ} \mathrm{C}\right)$ because of greater cooling at night under the chambers. Coleman (1973) also reported small soil-surface $T$ biases beneath aluminum cylinders compared with non-covered controls. Matthias et al. (1980) showed that for short chamber deployments (20 min), $\Delta T_{\mathrm{s}}$ $(2 \mathrm{~cm})$ was $\leq 1^{\circ} \mathrm{C}$ for an insulated reflective galvanized steel chamber. For longer deployment periods (hours to days), much larger $\Delta T_{\mathrm{s}}$ was measured for plexiglass $\left(+5^{\circ} \mathrm{C}\right)$, metal $\left(-14^{\circ} \mathrm{C}\right)$ and insulated reflective steel $\left(-18^{\circ} \mathrm{C}\right)$ chambers. Similarly, $\Delta T_{\mathrm{s}}(2 \mathrm{~cm})$ averaged $-4^{\circ} \mathrm{C}$ under reflective acrylic plastic chambers during $8-\mathrm{h}$ deployments under clear daytime conditions (Rochette et al., 1997).

Soil-surface temperature depends on net radiation and the partitioning of that energy into latent heat, sensible heat, and soil heat flux. Maintaining the same energy fluxes inside and outside the chamber is virtually impossible, so air and/or soil temperatures inside the chamber are likely to differ from the outside values. Soil temperature should be monitored during short and long deployments to assess potential impacts on soil respiration and to allow for eventual corrections of $F_{\mathrm{c}}$. For short deployments $(<1 \mathrm{~h})$ correction is not possible, because it is unknown how fast $\mathrm{CO}_{2}$ production responds to changing $T_{\mathrm{s}}$, or what additional delay occurs before resulting changes in the soil $\left[\mathrm{CO}_{2}\right]$ profile are reflected in $F_{\mathrm{c}}$. For longer deployments simple mathematical relationships may compensate for $T_{\mathrm{s}}$ changes (Lloyd \& Taylor, 1994; Palmer-Winkler et al., 1996); however, such corrections are likely to be imperfect, because they fail to account for interactions with other regulating variables, or for lateral diffusion that is likely to occur in response to the altered soil $\left[\mathrm{CO}_{2}\right]$ profile.

Insulated and reflective chambers are usually adequate to prevent large differences in both air temperature $\left(T_{\mathrm{a}}\right)$ and $T_{\mathrm{s}}$ for short deployments $(\leq 1 \mathrm{~h})$ (Matthias et al., 1980). Such chambers inhibit energy exchange with the atmosphere and rely on the thermal inertia of the system to limit $T$ variations. It is then assumed that remaining small variations in $T_{\mathrm{s}}$ and $T_{\mathrm{a}}$ have negligible effects on $F_{\mathrm{c}}$ during the short deployment period. During long deployments $(>1 \mathrm{~h})$, chamber design should focus on limiting $\Delta T_{\mathrm{s}}$ to avoid modifying the soil respiration rate that was intended to be measured. Matthias and Peralta-Hernández (1998) estimated optimal chamber wall emissivity and reflectivity for maintaining $T_{\mathrm{s}}$ under an opaque chamber equal to that of non-covered soil. The values predicted by their mathematical model differed depending on whether the chamber was deployed on dry or wet soil, indicating that chamber wall properties should differ under contrasting experimental conditions. Intuitively, $\Delta T_{\mathrm{s}}$ should be largest for deployments on dry soil under clear sky and smallest on wet soil under cloudy (or shaded) conditions; however, there is very little information to help chamber users design a chamber that limits $\Delta T_{\mathrm{s}}$ under various environmental conditions (exposed vs. shaded, dry vs. wet, daytime vs. night-time, etc.), and significant $\Delta T_{\mathrm{s}}$ should be expected when chambers are left in place for $>1 \mathrm{~h}$.

\section{Air Temperature}

Increases in $T_{\mathrm{a}}$ of 1 to $2^{\circ} \mathrm{C}$ during 10 min were measured in clear lexan chambers (Goulden \& Crill, 1997), while Matthias et al. (1980) reported differences between inside and outside $T_{\mathrm{a}}$ of $\leq 2^{\circ} \mathrm{C}$ for reflective insulated metal cham- 
bers, $15^{\circ} \mathrm{C}$ for metal chambers, and $27^{\circ} \mathrm{C}$ for plexiglass chambers after 20 -min deployment periods. Air temperature changes inside chambers can affect $F_{\mathrm{c}}$ measurements by inducing variations in air pressure $(P)$ or volume. Expansion or contraction of chamber air in response to changes in its temperature acts as a piston pushing the air into or pulling the air out of soil beneath a non-vented chamber, thereby substantially altering the measured gas flux across the soil surface (Hutchinson \& Livingston, 2001). Addition of a venting tube overcomes this problem, but the resultant mass flow through the vent causes leakage or contamination problems if chamber $\mathrm{CO}_{2}$ concentration $\left(\left[\mathrm{CO}_{2}\right]_{\mathrm{ch}}\right)$ differs from ambient $\mathrm{CO}_{2}$ concentration $\left(\left[\mathrm{CO}_{2}\right]_{\mathrm{amb}}\right)$. For example, across the range of headspace warming rates depicted in Fig. 12-1, $\mathrm{CO}_{2}$ loss expressed in units of a surface flux represents a nontrivial fraction of soil respiration rates that are commonly observed.

Energy balance calculations and in situ measurements (Matthias \& PeraltaHernández, 1998) indicate that $T_{\mathrm{a}}$ tends to be close to the surface $T_{\mathrm{s}}$ in chambers. Therefore, chamber designs that minimize $\Delta T_{\mathrm{s}}$ result in significant $T_{\mathrm{a}}$ variations, and long chamber deployments will almost inevitably be affected by the resulting pressure (or volume) changes. Correcting for leaks when temperature increases and air expands during deployment is straightforward if a vent is present (Table 12-1). In this case $P$ remains essentially constant and the effect of an increase in $T$ can be seen as a "virtual" increase in volume, even if in reality, air flowing through the vent mixes with ambient air. Under such conditions (increasing $T$ with constant $P$ and humidity), built-in functions of most portable $\mathrm{CO}_{2}$ analyzers correct for $T$-induced gas density variations. Analysis of sample and standard gases under prescribed laboratory $T$ and $P$ conditions also will eliminate the effects of rising chamber $T_{\mathrm{a}}$. Corrections for a decreasing $T$ trend during deploy-

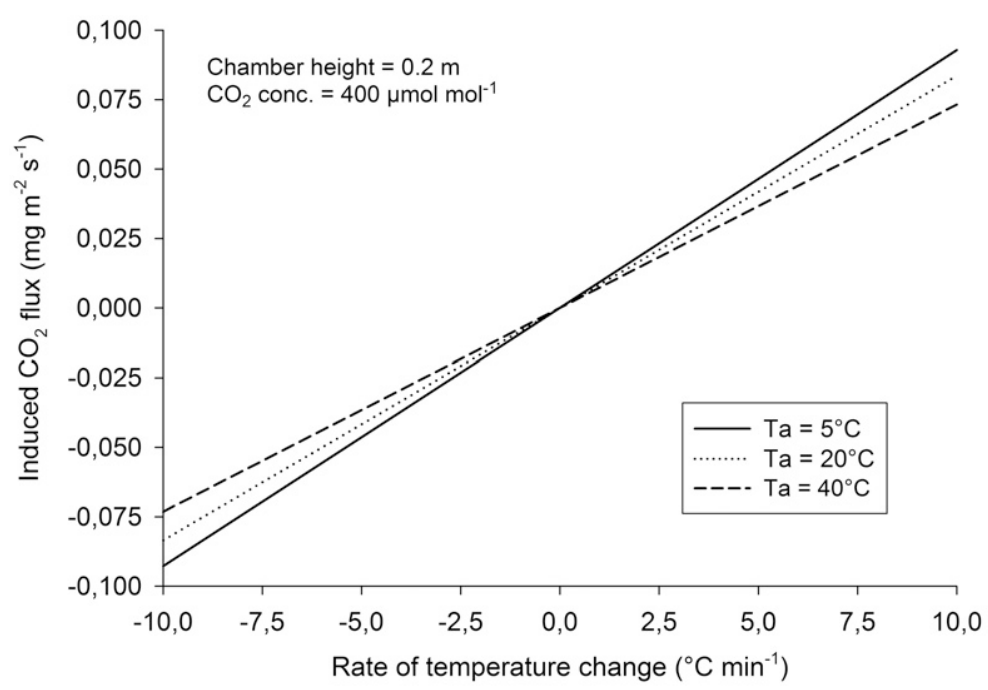

Fig. 12-1. Impact of chamber air temperature $\left(T_{\mathrm{a}}\right)$ variations on mass-flow $\mathrm{CO}_{2}$ flux through the venting tube of a non-steady-state chamber. The $\mathrm{CO}_{2}$ flux is expressed per unit of soil area covered by the chamber. (Flux leaving the chamber is considered positive). 
Table 12-1. Corrections for biases in $F_{\mathrm{c}}$ associated with pressure effects induced by chamber air temperature $\left(T_{\mathrm{a}}\right)$ variations in vented chambers.

\begin{tabular}{|c|c|}
\hline Type & Correction \\
\hline \multirow[t]{5}{*}{ FT-SS } & $\begin{array}{l}\text { Analysers usually have a built-in function to account for differences in } T_{\mathrm{a}} \text { between air } \\
\text { entering and leaving the chamber. }\end{array}$ \\
\hline & If not, all $\left[\mathrm{CO}_{2}\right]$ readings must be corrected using ideal gas law: \\
\hline & {$\left[\mathrm{CO}_{2}\right]_{\text {(corrected) }}=\left[\mathrm{CO}_{2}\right]_{\text {(measured) }} \times\left(T_{\text {a(measured) }} / T_{\text {a(calibration) }}\right)$.} \\
\hline & $\begin{array}{l}\text { The analyzer temperature response needs to be determined empirically if it doesn't } \\
\text { follow the ideal gas law. }\end{array}$ \\
\hline & $F_{\mathrm{c}}$ is then calculated using $\left[\mathrm{CO}_{2}\right]_{\text {(corrected) }}$ values. \\
\hline NFT-SS & $\begin{array}{l}\text { If } T_{\mathrm{a}} \text { is measured, corrections are the same as for NFT-NSS chambers. Because } T_{\mathrm{a}} \text { is not } \\
\text { usually measured in NFT-SS chambers and because of the long periods of deployment } \\
\text { (succession of cooling and warming periods), we recommend against venting NFT-SS } \\
\text { chambers (see text). }\end{array}$ \\
\hline \multirow[t]{6}{*}{ FT-NSS } & If $T_{\mathrm{a}}$ increases during deployment: \\
\hline & $\begin{array}{l}\text { Analyzers usually have a built-in function to account for variations in } T \text {. If not, all } \\
{\left[\mathrm{CO}_{2}\right] \text { must be corrected using ideal gas law: }}\end{array}$ \\
\hline & {$\left[\mathrm{CO}_{2}\right]_{\text {(corrected) }}=\left[\mathrm{CO}_{2}\right]_{\text {(measured) }} \times\left(T_{\text {a(measured })} / T_{\text {a(calibration })}\right)$} \\
\hline & $\begin{array}{l}\text { The analyzer temperature response needs to be determined empirically if it doesn't } \\
\text { follow the ideal gas law. }\end{array}$ \\
\hline & $F_{\mathrm{c}}$ is then calculated using $\left[\mathrm{CO}_{2}\right]_{\text {(corrected) }}$ values. \\
\hline & $\begin{array}{l}\text { If } T_{\mathrm{a}} \text { decreases during deployment: Same corrections will be imperfect because of } \\
\text { ambient air contamination. }\end{array}$ \\
\hline \multirow[t]{2}{*}{ NFT-NSS } & $\begin{array}{l}\text { Store air samples at a pressure }>100 \mathrm{kPa} \text { to prevent problems associated with volume } \\
\text { contraction. If } T_{\mathrm{a}} \text { increases during deployment: Air samples of a same chamber } \\
\text { deployment must be analyzed at same pressure and temperature (i.e., successively). } \\
\text { Using molar volume determined at chamber temperature in Eq. [3] corrects for } \\
\text { differences in sample temperature between sampling and analysis. }\end{array}$ \\
\hline & $\begin{array}{l}\text { If } T_{\mathrm{a}} \text { decreases during deployment: Same corrections will be imperfect because of } \\
\text { ambient air contamination. }\end{array}$ \\
\hline
\end{tabular}

ment are more troublesome. Under this scenario, headspace air contracts and is contaminated by outside air, so corrections require knowing the $\left[\mathrm{CO}_{2}\right]$ of the air entering the vent. Because this concentration is usually unknown, chamber designs that result in rapid cooling of chamber air during deployment should be avoided.

\section{Humidity}

Variations in $\mathrm{CO}_{2}$ flux across the soil surface are related to changes in soil water content $\left(H_{\mathrm{s}}\right)$, primarily because of its strong influence on both solution phase and gas phase transport rates. The activity of aerobic decomposers is maximal when approximately $60 \%$ of the total soil porosity is occupied by water (Linn \& Doran, 1984). Their activity is reduced at lower water contents by slow diffusion of substrates and products, and at higher water contents by a restricted $\mathrm{O}_{2}$ supply. Chambers or collars can modify soil moisture, and thus $F_{\mathrm{c}}$, by intercepting or excluding rainfall and run-off water, reducing evaporation (Edwards, 
1974) and redistributing soil water that evaporates and then condenses and runs down the chamber walls. Chambers should not be used during rainfall, as an infiltrating wetting front outside the chamber may induce mass flow of gases into the chamber.

The humidity of headspace air $\left(H_{\mathrm{a}}\right)$ often increases during deployment and can have a significant effect on the measurement of $F_{\mathrm{c}}$. Water evaporated at the soil surface increases headspace air pressure (or volume) and creates mass flow problems similar to those induced by rising temperature (Welles \& McDermitt, 2005). For example, in a $0.2-\mathrm{m}$ high non-steady-state chamber $\left(T_{\mathrm{a}}=20^{\circ} \mathrm{C}\right)$ where evaporation increases relative humidity from 0 to $100 \%$ during a 1-min deployment (evaporation rate $=3.3 \mathrm{mmol} \mathrm{m}^{-2} \mathrm{~s}^{-1}$ ), mass flow of $\mathrm{CO}_{2}$ out the chamber vent would be equivalent to $F_{\mathrm{c}}=0.06 \mathrm{mg} \mathrm{m}^{-2} \mathrm{~s}^{-1}$ (Fig. 12-2). Evaporation increases with $T_{\mathrm{a}}, T_{\mathrm{s}}$, and soil water content and cannot be stopped during chamber deployment; however, it can be minimized by using reflective and insulated chambers that decrease available energy at the soil surface. A major difference between $T_{\mathrm{a}}$ - and $H_{\mathrm{a}}$-induced $P$ variations is that the mole fraction of $\mathrm{CO}_{2}$ is conserved during the former but not the latter, because the added water dilutes $\mathrm{CO}_{2}$ in the chamber. Therefore, corrections for the effect of increasing $H_{\mathrm{a}}$ are not as straightforward as for increasing $T_{\mathrm{a}}$, and they vary with chamber type. The corrections shown in Table 12-2 address only the dilution problem; other corrections may be needed if the $\mathrm{CO}_{2}$ analyzer exhibits cross-sensitivity to water vapor.

Water vapor condenses on the chamber walls except when the deployment period is short or the evaporation rate is low. The condensed water influences chamber performance by changing the headspace volume and by absorption-desorption of $\mathrm{CO}_{2}$. These effects can be estimated using simple calculations. For a 3-

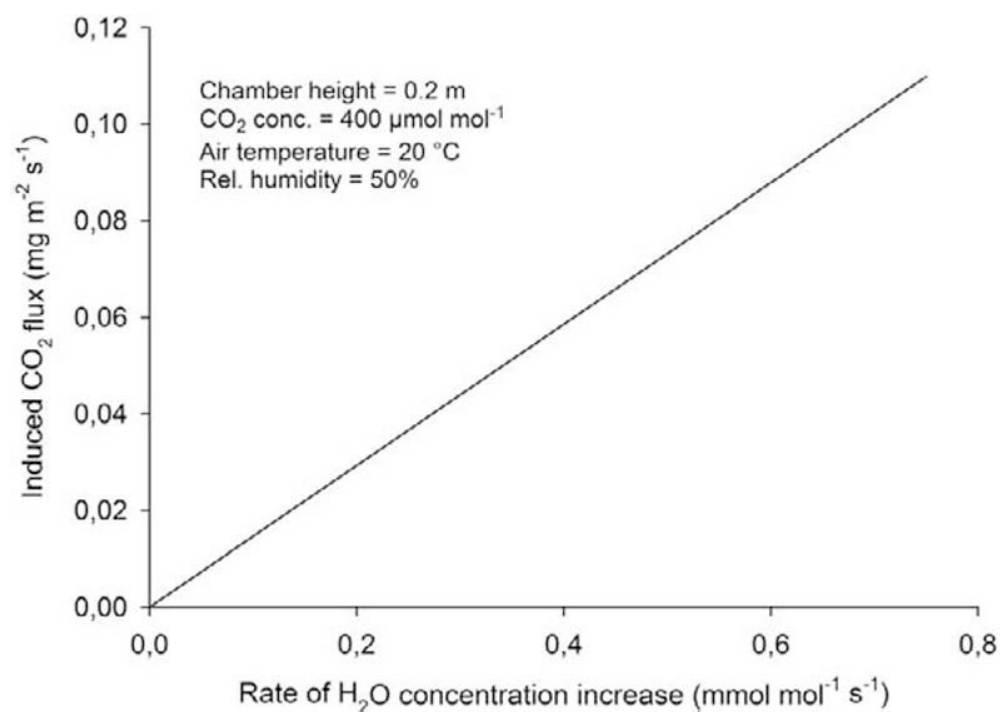

Fig. 12-2. Impact of chamber air humidity variations on mass-flow $\mathrm{CO}_{2}$ flux through the venting tube of a non-steady-state chamber. The $\mathrm{CO}_{2}$ flux is expressed per unit of soil area covered by the chamber. (Flux leaving the chamber is considered positive). 
Table 12-2. Soil-surface $\mathrm{CO}_{2}$ flux $\left(F_{\mathrm{c}}\right)$ corrections for removing pressure/volume biases induced by changes in water vapor partial pressure $(e a)$ in vented chambers.

\begin{tabular}{ll}
\hline Type & Correction \\
\hline FT-SS & $\begin{array}{l}\text { Measured } C_{\mathrm{i}}, C_{\mathrm{o}}, \text { and } f \text { must be corrected to the same humidity. Examples: If } C_{\mathrm{i}}, C_{\mathrm{o}}, \\
\text { and } f \text { are all measured on dried air samples, no corrections are needed. }\end{array}$ \\
& If $C_{\mathrm{i}}$ and $C_{\mathrm{o}}$ are measured on dried air samples and $f$ at incoming air humidity: \\
& $\begin{aligned} C_{\text {o(corrected) }} & =C_{\text {o(dry) }} \times\left(1-e a_{\text {(incoming) }} / P\right) \text { and } C_{\mathrm{i}(\text { corrected) }} \\
& =C_{\mathrm{i}(\text { dry) }} \times\left(1-e a_{\text {(incoming) }} / P\right) \text { or } f_{\text {(corrected) }}=f_{\text {(measured) }} \times\left(1-e a_{\text {(incoming) }} / P\right) .\end{aligned}$ \\
& If $C_{\mathrm{i}}, C_{\mathrm{o}}$, and $f_{\text {(incoming) }}$ are all measured on undried air samples: \\
& $C_{\text {o(corrected) }}=C_{\text {o(measured) }} \times\left(1-\left(e a_{\text {(outgoing) }}-e a_{\text {(incoming) }}\right) / P\right)$
\end{tabular}

NFT-SS Correction is not possible. Evapotranspiration affects $P$ until chamber air saturates. Then, $e a$-induced $P$ variations amplify temperature-induced $P$ variations as water vapor condenses and re-evaporates in response to cooling and warming cycles.

FT-NSS and If $\left[\mathrm{CO}_{2}\right]$ is measured on dried air samples: $F_{\mathrm{c}(\text { corrected })}=F_{\mathrm{c} \text { (measured })} \times\left(1-e a_{\text {(mean })} / P\right)$ NFT-NSS where $e a_{\text {(mean) }} / P=$ mean water vapor mole fraction during deployment.

If $\left[\mathrm{CO}_{2}\right]$ is measured on air samples not dried:

$F_{\text {c(corrected) }}=F_{\text {c(measured) }}+\left(F_{\mathrm{e}} \times\left[\mathrm{CO}_{2}\right]_{\text {(mean })} /\left(1-e a_{\text {(mean) }} / P\right)\right.$

where $F_{\mathrm{e}}=$ evaporation rate (in mol area ${ }^{-1} \mathrm{time}^{-1}$ ), and $\left[\mathrm{CO}_{2}\right]_{\text {(mean) }}=$ mean $\left[\mathrm{CO}_{2}\right]_{\mathrm{ch}}$ during deployment (Welles \& McDermit, 2002).

$\dagger C_{\mathrm{i}}, \mathrm{CO}_{2}$ concentration of the incoming air; $C_{\mathrm{o}}, \mathrm{CO}_{2}$ concentration of the ougoing air; $P$, Barometric pressure in chamber; $f$, Flow rate through the chamber; $e a$, Water vapour partial pressure.

L chamber (height $=0.15 \mathrm{~m}$; cross-section $=200 \mathrm{~cm}^{2}$ ) a 1-mm-thick layer of condensed water occupies about $3 \%$ of the chamber volume, thereby causing a 3\% overestimation of $F_{\mathrm{c}}$ if there is no $\mathrm{CO}_{2}$ exchange between the water and headspace air. This effect is proportional to the ratio of chamber inner wall surface area to volume, so, for a given chamber shape, it decreases as the chamber size increases. The condensed water may also serve as a sink for $\mathrm{CO}_{2}$ when its concentration increases, but this effect is small because Henry's Law coefficient for $\mathrm{CO}_{2}$ in water is close to unity at $20^{\circ} \mathrm{C}$ (approximately 2 near $0^{\circ} \mathrm{C}$ ). Therefore, the faster the exchange of $\mathrm{CO}_{2}$ between gaseous and liquid phases, the smaller the effect of condensed water on calculation of $F_{\mathrm{c}}$, because the equilibrium concentration of dissolved $\mathrm{CO}_{2}$ in water will be very close to its concentration in chamber air. As a result, the greatest possible impact of condensed water in this example would be $3 \%$ overestimation of $F_{\mathrm{c}}$.

\section{Pressure Fluctuations}

Theoretical analysis of near-surface atmospheric processes predicts that mechanical mixing and barometric $P$ fluctuations above an agricultural soil surface add little to the diffusive flux of gases in soil (Kimball \& Lemon, 1971); however, there is empirical evidence that turbulence may have a greater effect than predicted by theory; e.g., Kimball (1983) attributed a 25\% increase in gas flux across a dry sandy soil surface to turbulence-induced $P$ fluctuations. A properly designed venting tube transmits changes in external atmospheric $P$ to the 
chamber headspace, thereby minimizing suppression by the chamber of their effect on $F_{\mathrm{c}}$ (Hutchinson \& Mosier, 1981; Livingston \& Hutchinson, 1995). The venting tube also overcomes the effects of chamber volume reductions during chamber deployment and headspace air sampling (Hutchinson \& Livingston, 2001).

\section{Chamber Air Mixing Regime}

Most chamber estimates of $F_{\mathrm{c}}$ are based on measurements of mean $\left[\mathrm{CO}_{2}\right]_{\mathrm{ch}}$. Therefore, adequate mixing of chamber air is required to ensure that air samples are representative of that mean. Matthias et al. (1980) reported homogeneous air mixing in a short non-flow-through non-steady-state chamber. In contrast, aliquots of gas have been shown to take up to $12 \mathrm{~min}$ to completely mix within a 49-L flow-through non-steady-state chamber (Ambus \& Robertson, 1998). Accordingly, fans are often used to increase mixing intensity inside the chamber (Rochette et al., 1997). Fans also can be used to help generate air mixing intensities that match pre-deployment levels. Mass transfer at the soil surface is characterized by a laminar layer of air through which transfer is diffusive and above which transfer is convective. The thickness of the diffusive layer decreases with increasing wind velocity. At steady-state, the vertical $\left[\mathrm{CO}_{2}\right]$ gradient between soil and air is in equilibrium with the thickness of the interfacial layer, so $F_{\mathrm{c}}$ equals soil respiration. A change in turbulence regime modifies the thickness of the diffusive layer, disrupts the equilibrium and results in an adjustment period during which $F_{\mathrm{c}}$ is not equal to soil respiration. Therefore, deploying a chamber in which the turbulence intensity differs from pre-deployment conditions may result in transient effects on gas transfer and biased soil respiration estimates (Matthias et al., 1980; Healy et al., 1996; Hutchinson et al., 2000).

There are several reports of the effects of chamber air mixing intensity on $F_{\mathrm{c}}$ estimates. Reicosky et al. (1997) measured $F_{\mathrm{c}}$ that was 10 times larger in a large fan-mixed chamber than in a small air-stream mixed chamber. Hanson et al. (1993) measured a seven-fold increase in $F_{\mathrm{c}}$ when wind speed inside a nonsteady-state chamber was increased from 0 to $0.6 \mathrm{~m} \mathrm{~s}^{-1}$. Le Dantec et al. (1999) and Janssens et al. (2000) reported that $F_{\mathrm{c}}$ measurements were sensitive to headspace fan-mixing and concluded that the wind speed inside the chamber should mimic pre-deployment conditions. On the other hand, Norman et al. (1997) mentioned that the use of a fan in a non-steady-state chamber (Crill, 1991) had no effect on $F_{\mathrm{c}}$ measurement.

Rochette (unpublished data, 2001) assessed the performance of a flowthrough non-steady-state chamber in which $0,1,2$, or 4 mixing fans were used (Fig. 12-3). Measurements of $F_{\mathrm{c}}$ were made over mineral soil with relatively low porosity. The square chamber (cross-section, $0.3 \mathrm{~m}^{2}$; height, $0.2 \mathrm{~m}$ ) was covered with $1-\mathrm{cm}$ insulation material and then reflective aluminum foil (Rochette et al., 1997). Four individually-controlled fans (LI-6000-17, LI-COR Inc., Lincoln, $\mathrm{NE}$ ) were mounted horizontally under the top of the chamber. We first compared measurements made with and without one fan operating during three days in June and July 2000 . The turbulence provided by the air flow alone ( 0 fan) was not sufficient to ensure adequate mixing inside the chamber, resulting in a noisy 


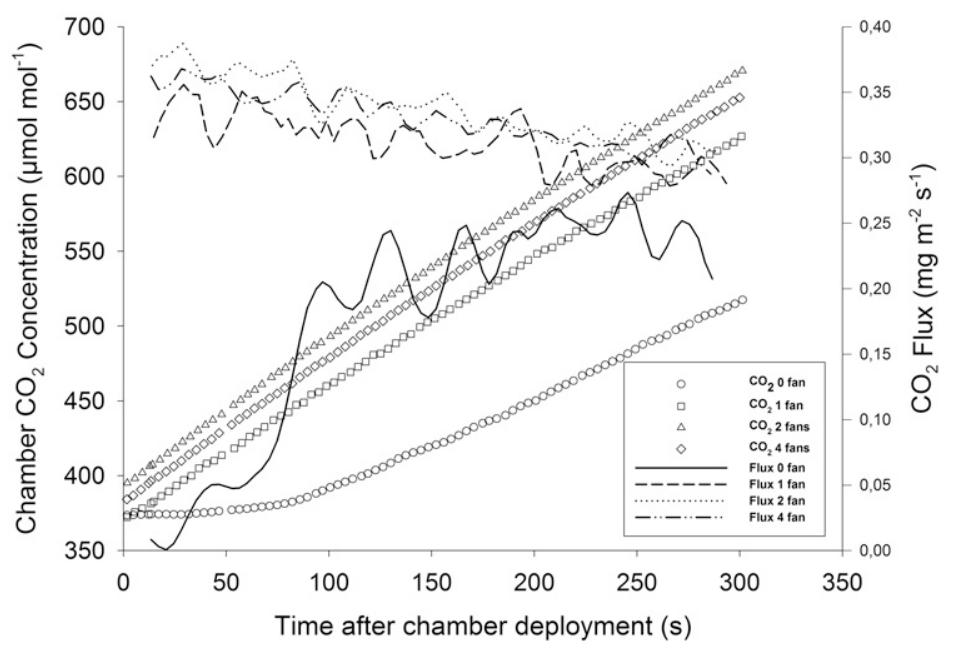

Fig. 12-3. Influence of fan-mixing intensity $(0,1,2$, or 4 fans running) of chamber air on chamber $\mathrm{CO}_{2}$ concentration and soil-surface $\mathrm{CO}_{2}$ flux measurements in a flow-through non-steady-state chamber.

$\left[\mathrm{CO}_{2}\right]_{\mathrm{ch}}$ signal and high variability in $F_{\mathrm{c}}$ determination. Total $\mathrm{CO}_{2}$ accumulated in the chamber during 2-min deployments was usually lower without a fan than with one fan running, but differences were not the same for all $3 \mathrm{~d} . \mathrm{CO}_{2}$ accumulations without a fan were 100,73 , and $33 \%$ of those when one fan was used on day of year (DOY) 188, 206, and 208, respectively. Differences among days suggest that other factors such as wind speed and air-filled porosity at the time of measurement were probably involved. On DOY 208, we also measured $F_{\mathrm{c}}$ using $0,1,2$, or 4 fans to mix the chamber headspace. Flux estimates using 1, 2, or 4 fans were nearly identical (Fig. 12-3), suggesting that only one small fan was needed to achieve near-perfect headspace mixing. Absence of a fan resulted in flux estimates that started low but increased rapidly during the first 2 min of the deployment period. Estimates of $F_{\mathrm{c}}$ without a fan were 10, 65, and $92 \%$ of fanmixed estimates after 0,2 , and 5 min, respectively. Results of simulation studies suggest that deployment of a chamber in which gas transfers are diffusive over a surface previously exposed to a perfectly mixed atmosphere, results in an instantaneous decrease in $F_{\mathrm{c}}$ (Healy et al., 1996). The lower early-deployment $F_{\mathrm{c}}$ values obtained with no fan agree with these predictions.

The above experimental and simulation results support previous observations that $\mathrm{CO}_{2}$ diffusion into a flow-through non-steady-state chamber depends on headspace mixing intensity, and that to avoid biased flux estimates, chamber users must match headspace mixing intensity to pre-deployment conditions as closely as possible. For example, a low-turbulence chamber may perform well under a dense plant canopy where the soil is shaded from direct solar radiation and the air is calm, but the same chamber may underestimate $F_{\mathrm{c}}$ in open agricultural fields where the soil surface is exposed and turbulent mixing is usually high. Alternatively, use of a highly turbulent chamber in a previously diffusive environ- 
ment may result in artificially enhanced $F_{\mathrm{c}}$ estimates (Hutchinson et al., 2000). In addition to their effects on $\mathrm{CO}_{2}$ diffusion, fans with vertical orientation or high flow rate may induce mass flows by altering air pressure above the soil surface, especially when the soil's air-filled porosity is high. Accordingly, fans should be mounted horizontally away from the soil surface, and excessive fan mixing should be avoided (Norman et al., 1992; Rochette et al., 1997).

\section{Chamber Headspace Carbon Dioxide Concentration}

Soil microbial respiration can be influenced by high $\left[\mathrm{CO}_{2}\right]$ and low $\left[\mathrm{O}_{2}\right]$ that may occur during long chamber deployments. For example, MacFayden (1973) reported that the soil respiration rate measured at $0.0017 \mathrm{~m}^{3} \mathrm{CO}_{2} \mathrm{~m}^{-3}$ was 0 to $63 \%$ smaller than in a $\mathrm{CO}_{2}$-free atmosphere, and $\mathrm{O}_{2}$ variations resulted in modified $F_{\mathrm{c}}$ during laboratory incubations (Parr \& Reuszer, 1959; van Cleve et al., 1979; Sharkov, 1984). Koizumi et al. (1991) found that soil respiration was stimulated by below-ambient $\left[\mathrm{CO}_{2}\right]$, and low $\left[\mathrm{CO}_{2}\right]_{\mathrm{ch}}$ has been suggested as the reason for elevated $F_{\mathrm{c}}$ measured in non-flow-through steady-state chambers (alkali traps) (MacFayden, 1973; Bekku et al., 1997). Although large $\mathrm{CO}_{2}$ concentrations and $\mathrm{O}_{2}$ depletion can have significant effects on soil respiration during long deployments, they are not likely to be a factor for shorter $(<1 \mathrm{~h})$ deployments.

In addition to its direct effect on microbial respiration, headspace $\left[\mathrm{CO}_{2}\right]$ also influences upward transport of the gas away from its site of production in soil. Under steady-state conditions, the rate of $\mathrm{CO}_{2}$ emission at the soil surface is equal to its sub-surface rate of production, and the vertical $\left[\mathrm{CO}_{2}\right]$ gradient is constant. When a non-steady-state chamber is deployed, $\left[\mathrm{CO}_{2}\right]$ immediately above the soil surface increases, thereby reducing the gradient and thus the $\mathrm{CO}_{2}$ flux into the chamber (Matthias et al., 1978; Healy et al., 1996). The difference between the constant production rate and the decreasing flux into the chamber accumulates in the soil profile beneath the chamber, partially re-building the gradient (Rayment, 2000). The rate of decline in the surface flux is greatest immediately after deployment, then decreases gradually as gradient re-adjustment proceeds at greater soil depth (Naganawa \& Kyuma, 1991; Healy et al., 1996; Rochette et al., 1997). In contrast, for a steady-state chamber where $\left[\mathrm{CO}_{2}\right]$ is maintained constant, modification of the $\left[\mathrm{CO}_{2}\right]$ gradient influences $F_{\mathrm{c}}$ measurements only until a new steady state is achieved and $F_{\mathrm{c}}$ is again equal to the production rate. Options for minimizing the effects of changing $\left[\mathrm{CO}_{2}\right]_{\mathrm{ch}}$ on $F_{\mathrm{c}}$ will be addressed in the subsequent "chamber techniques" section.

\section{Leaks and Site Disturbance}

Chamber techniques are based on the assumption that the chamber and its underlying soil column are isolated from the surrounding environment, or that mass exchange with the outside is measured. Inadequate isolation induces biases in $F_{\mathrm{c}}$ estimates if $\left[\mathrm{CO}_{2}\right]_{\mathrm{ch}} \neq\left[\mathrm{CO}_{2}\right]_{\mathrm{amb}}$. Examples of openings through which headspace gases may leak or become contaminated by ambient air include the venting tube and imperfect seals at the chamber-collar and chamber- or collar-soil joints. 
Model simulations predict that a properly designed vent avoids most unwanted pressure differences between the inside and outside of the chamber without significant risk of leakage or contamination (Hutchinson \& Livingston, 2001); however, Conen and Smith (1998) recently proposed that a venting tube may create more significant problems than it solves, because of the Venturi effect caused by wind blowing over the tube's open end. They reported that soil $\mathrm{N}_{2} \mathrm{O}$ emission measured by vented aluminum chambers was sometimes significantly greater than when similar non-vented chambers were used, and they attributed the difference to upward mass flow of air beneath the vented chambers due to the Venturi effect. Hutchinson and Livingston (2001) argued that the difference in flux estimates noted by Conen and Smith (1998) may instead have been due to $T_{\mathrm{a}}$-related pressure variations beneath the non-vented chambers, but cautioned that the vent must be properly sized, located, and shielded to minimize the potential for depressurization. Optimum vent tube diameter and length can be computed from the equations in Hutchinson and Mosier (1981) or taken from the nomograph in Hutchinson and Livingston (2002), but existing literature offers little guidance regarding optimum vent tube location and shielding. Intuitively, the vent's external opening should be as near the soil surface as practical, because wind speed increases logarithmically with height in the lower atmospheric boundary layer.

Norman et al. (1992) estimated that leaks through the venting tube of a 5-L flow-through non-steady-state chamber were equivalent to a surface flux of $0.0022 \mathrm{mg} \mathrm{m}^{-2} \mathrm{~s}^{-1}$ (approximately $2 \%$ of the average summer $F_{\mathrm{c}}$ in a forest soil) for every $20 \mu \mathrm{mol} \mathrm{mol}{ }^{-1}$ difference between $\left[\mathrm{CO}_{2}\right]_{\mathrm{ch}}$ and $\left[\mathrm{CO}_{2}\right]_{\mathrm{amb}}$. Total leakage through the vent, imperfect seals and components of the air circulation system (tubing, filter, or pump) can be evaluated by sealing the chamber system to a nonemitting surface, adjusting $\left[\mathrm{CO}_{2}\right]_{\mathrm{ch}}$ to be different than $\left[\mathrm{CO}_{2}\right]_{\mathrm{amb}}$, and then monitoring the rate of change in $\left[\mathrm{CO}_{2}\right]_{\mathrm{ch}}$ over time. In flow-through chamber systems, leaks in the air circulation system (tubing and pump) would be easily detected with this test as leak-induced pressure differences would result in substantial $\mathrm{CO}_{2}$ flux out or in the chamber through the venting tube. Our laboratory tests using a 50-L chamber (vent: $0.01 \mathrm{~m}$ i.d. $\times 0.25 \mathrm{~m}$ length) yielded very small leaks0.0001 or $0.0002 \mathrm{mg} \mathrm{m}^{-2} \mathrm{~s}^{-1}$ when wind speed over the chamber was 0 or $3.5 \mathrm{~m} \mathrm{~s}^{-1}$, respectively, and the difference between $\left[\mathrm{CO}_{2}\right]_{\mathrm{ch}}$ and $\left[\mathrm{CO}_{2}\right]_{\mathrm{amb}}$ was 800 $\mu \mathrm{mol} \mathrm{mol}{ }^{-1}$. Interestingly, running the soil respiration system pump (LI-6200, LICOR Inc, Lincoln, NE) with or without one fan running had no impact on the leaks. These results confirm that in absence of a pressure difference between the outside and inside of the chamber, leakage through the vent should be small in most situations.

A closed-cell foam gasket or water can provide a good seal between the collar and chamber. A good seal between chamber and soil requires insertion of chamber walls into the soil (Healy et al., 1996). This operation can alter the soil resistance to gas exchange if openings are created at the soil-wall interface. Matthias et al. (1980) measured increases of up to $250 \%$ in $\mathrm{N}_{2} \mathrm{O}$ fluxes when a collar was inserted inside a larger chamber. The impacts of soil disturbance will be greater when soil diffusivity is lower (wet or compacted soils) because of the large vertical $\mathrm{CO}_{2}$ gradients in such soils (Norman et al., 1997). Push-in chambers are more subject to this problem, and high transient fluxes (from 0.66 to 
$0.3 \mathrm{mg} \mathrm{m}^{-2} \mathrm{~s}^{-1}$ in $40 \mathrm{~min}$ ) have resulted from their use shortly after rainfall (Norman et al., 1997). Such chambers can also bias $F_{\mathrm{c}}$ measurements by breaking surface crusts that sometimes form when soil dries (Rochette et al., 1997).

Most chamber users have solved the soil disturbance problems related to chamber insertion (as well as the difficulties associated with the insertion of larger chambers) by using collars that are installed prior to the measurements. Recommended delays between collar installation and measurements can vary from $1 \mathrm{~h}$ for shallow $(2 \mathrm{~cm})$ collars used with chambers that operate at $\left[\mathrm{CO}_{2}\right]_{\mathrm{ch}}=$ $\left[\mathrm{CO}_{2}\right]_{\text {amb }}$ (Norman et al., 1997) to several weeks for deep collars $(15 \mathrm{~cm})$ within which there was substantial root damage (Hutchinson \& Livingston, 2002); however, use of collars does not solve all problems. Norman et al. (1997) reported that collars inserted to shallow depths, or in non-cohesive (e.g., organic) materials, tend to become loose after repeated measurements and lead to erroneously high $F_{c}$; they recommend using metal spikes to stabilize the collar. Collars also can affect soil moisture by preventing run-off, soil temperature by shading the soil and gas exchange by the formation of shrinkage cracks at the collar-soil interface. When conditions inside a collar differ substantially from the outside, it should be relocated.

Leakage or contamination also may occur by lateral diffusion of $\mathrm{CO}_{2}$ beneath the chamber (collar) wall in response to deformation of the vertical $\left[\mathrm{CO}_{2}\right]$ gradient in soil. Healy et al. (1996) estimated the magnitude of lateral diffusion for a chamber resting on soil surface $(0 \mathrm{~cm}$ insertion depth) by comparing one- and three-dimensional simulations of gas diffusion in the soil-chamber continuum. The decrease in $F_{\mathrm{c}}$ after $30 \mathrm{~min}$ was three times larger for the threedimensional case. Wall insertion depths that ensure minimal leaks increase with increasing deployment time and soil gas diffusivity. Model simulations suggest that insertion depths required to limit biases in $F_{\mathrm{c}}$ estimates to $<1 \%$ are $2.5 \mathrm{~cm}$ for 10-min deployments and $13 \mathrm{~cm}$ for 60-min deployments in a soil having air-filled porosity of $0.3 \mathrm{~m}^{3} \mathrm{~m}^{-3}$ (Hutchinson \& Livingston, 2001). In disturbed soil where convective flow can occur in cracks and voids, deeper insertion is probably required. For example, insertion to the bottom of the plough layer $(0.2 \mathrm{~m})$ was required to provide an adequate seal in recently ploughed fine-textured soils (Rochette, unpublished data, 2000).

The impact of lateral diffusion on $F_{\mathrm{c}}$ measurement is affected by the geometry of the chamber. The magnitude of such leaks is proportional to the perimeter of the chamber $\left(\mathrm{mg} \mathrm{CO}_{2} \mathrm{~m}^{-1} \mathrm{~s}^{-1}\right.$ ), while the flux of gas into the chamber ( $\mathrm{mg}$ $\mathrm{CO}_{2} \mathrm{~m}^{-2} \mathrm{~s}^{-1}$ ) increases with the area of soil covered by the chamber. Therefore, the impact on $F_{\mathrm{c}}$ determination decreases with increasing chamber width (proportional to "2/radius" for cylindrical chambers). Increasing chamber height also reduces leakage/contamination by decreasing the difference in $\left[\mathrm{CO}_{2}\right]$ inside and outside the chamber for a given $F_{\mathrm{c}}$.

\section{Chamber Design}

Chambers can be made of various rigid materials that don't react with $\mathrm{CO}_{2}$ (stainless steel, aluminum, acrylic plastic, polyvinyl chloride, etc.). Chamber geometry appears to have little direct effect on flux estimates as long as adequate air mixing is achieved (Hutchinson \& Livingston, 2001); however, the geometry 
can be altered to improve chamber performance under specific experimental conditions or to achieve specific scientific objectives. For example, Taller chambers experience a smaller increase in $\left[\mathrm{CO}_{2}\right]_{\mathrm{ch}}$ for a given $F_{\mathrm{c}}$ and are thus less subject to leaks, problems associated with humidity increases, and errors in volume determination. On the other hand, taller chambers make $T_{\mathrm{a}}$ and $H_{\mathrm{a}}$ control more difficult, may require a fan to achieve adequate mixing, and are less accurate for measuring small $F_{\mathrm{c}}$ (Rochette et al., 1997). Chambers with small cross-section can sample small spatial variations and can be used in inhomogeneous terrain (between rocks, vegetation, and tree roots), but they also are more sensitive to leaks and site disturbance, and cannot integrate spatial variability (Norman et al., 1997).

\section{Air Sampling and Carbon Dioxide Analysis}

Carbon dioxide concentration can be measured in real time during deployment or in the laboratory on samples taken earlier during chamber deployment. Most gas analyzers that can be used for near-continuous $\left[\mathrm{CO}_{2}\right]$ determination are based on the property of $\mathrm{CO}_{2}$ to absorb infrared radiation (IRGA). Differences between the absorbance of samples and a reference of known concentration have been determined using acoustic or radiation detectors, both of which are portable and adaptable to flow-through chamber systems (Rochette et al., 1991; Ambus \& Robertson, 1998; Welles \& McDermitt, 2002). When an analyzer is not available at the experimental site, air samples are usually taken using syringes or pre-evacuated glass vials, depending on the anticipated delay before analysis. In a comparative study, aluminum canisters and tedlar bags were best, while nylon and tygon were worst, for sample conservation during a 10-d period (Scott et al., 1999). High contamination (approximately $16 \% \mathrm{~d}^{-1}$ ) has been observed in samples stored in polypropylene syringes with a polyisoprene "piston gasket" and these syringes should not be used for storage longer than a few hours (Rochette \& Bertrand, 2003). Air-tight glass syringes provide a better seal but are expensive, cumbersome, and cannot be easily adapted to automated analysis. They also are subject to contamination when temperature at the time of sampling is higher than during storage or analysis. Pressurizing samples $(200 \mathrm{kPa})$ into pre-evacuated vials (12$\mathrm{mL}$ Exetainer, Labco, High Wycombe, England) using a syringe allows for travel over long distances and analysis on a gas chromatograph equipped with a headspace autosampler. Handling samples at above-ambient pressure minimizes contamination during storage (approximately $0.001 \mathrm{~m}^{3} \mathrm{~m}^{-3} \mathrm{~d}^{-1}$ ) and when a subsample is taken for analysis, and residual positive $P$ after analysis can be used to detect defective vials. We strongly recommend to evacuate the vials not more than a few days before use, to use fine needles $(26$ or $27 \mathrm{G}$ ) for evacuation and sampling, and to routinely evaluate the level of vacuum reached and how it evolves with time. Whenever chambers are used, samples should be taken from a source of known $\left[\mathrm{CO}_{2}\right]$ in the field following the same procedure as for chamber air samples. These samples should be stored and analyzed in the same way as the unknown samples to assess sample handling efficiency.

Gas chromatographs are extensively used for $\left[\mathrm{CO}_{2}\right]$ determination in air samples. They are most often used in the laboratory, but can be adapted for field operation (Christensen, 1983; Loftfield et al., 1992). General information for 
determination of $\left[\mathrm{CO}_{2}\right]$ using a gas chromatograph can be found in Lodge (1988) and Zibilske (1994). Several combinations of column, detector, and analysis conditions can be used. The choice depends, among other things, on required sensitivity, sample volumes, and constraints related to the simultaneous analysis of other gases. An example of a gas chromatograph (Model 3800, Varian, Walnut Creek, CA) configuration for $\left[\mathrm{CO}_{2}\right]$ determination on three detectors is given in Table 12-3. This gas chromatograph configuration allows for the simultaneous determination of $\mathrm{CH}_{4}, \mathrm{CO}_{2}, \mathrm{~N}_{2} \mathrm{O}$, and $\mathrm{O}_{2}$ in 5-mL samples during 5-min runs. Low and high $\left[\mathrm{CO}_{2}\right]$ are measured on the flame ionization and thermal conductivity detectors, respectively. The electron capture detector line configuration is optimized for $\mathrm{N}_{2} \mathrm{O}$ but can provide back-up estimates for high $\left[\mathrm{CO}_{2}\right]$. The performance of all three configurations can be modified by changing sample volume, detector $T$, etc. Use of sampling loops helps keep the injected volume constant. Gas chromatographs can be equipped with headspace autoinjectors for automation. IRGA analyzers also can be used in the laboratory for small air samples (Parkinson, 1981; Bekku et al., 1995).

The property of $\mathrm{CO}_{2}$ to react with alkali substrates has been used to quantify $\mathrm{CO}_{2}$ fluxes. Aqueous solutions of $\mathrm{NaOH}$ and $\mathrm{KOH}$ have been used for this purpose. Soda lime also can be used if required corrections are made for water formed during $\mathrm{CO}_{2}$ absorption (Minderman \& Vulto, 1973; Edwards, 1982; Grogan, 1998).

\section{CHAMBER TECHNIQUES}

Several types of chambers are used for in situ measurement of $F_{c}$. According to the classification scheme proposed by Livingston and Hutchinson (1995), all types can be grouped into steady-state (SS) chambers in which $F_{\mathrm{c}}$ is calculated under constant $\left[\mathrm{CO}_{2}\right]_{\mathrm{ch}}$ and non-steady-state (NSS) chambers in which $F_{\mathrm{c}}$ is calculated from the rate of change in $\left[\mathrm{CO}_{2}\right]_{\mathrm{ch}}$. Both classes can be further divided into flow-through (FT) or non-flow-through (NFT) types depending on whether air is circulated through the chamber. In the following sections, we suggest designs and operational protocols for optimizing each chamber type for $F_{\mathrm{c}}$ measurements.

\section{Flow-Through Steady-State Chambers}

As detailed earlier in this chapter, an increase in $\left[\mathrm{CO}_{2}\right]_{\mathrm{ch}}$ during chamber deployment has a direct impact on $F_{\mathrm{c}}$. Steady-state chambers are designed to reduce this impact by measuring $F_{\mathrm{c}}$ at constant $\left[\mathrm{CO}_{2}\right]_{\mathrm{ch}}$. In FT-SS chambers, $\left[\mathrm{CO}_{2}\right]_{\mathrm{ch}}$ is controlled by passing air through the chamber at a known constant rate

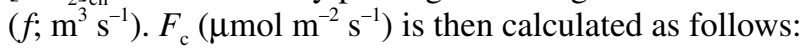

$F_{\mathrm{c}}=(f / A)\left(C_{\mathrm{o}}-C_{\mathrm{i}}\right) / M_{\mathrm{v}}$

where $A$ is the enclosed soil area, $M_{\mathrm{v}}\left(\mathrm{m}^{3} \mathrm{~mol}^{-1}\right)$ is the molar volume of air at chamber air temperature and pressure, and $C_{\mathrm{i}}$ and $C_{\mathrm{o}}$ are the $\left[\mathrm{CO}_{2}\right]\left(\mu \mathrm{mol} \mathrm{mol}^{-1}\right)$ of air entering and leaving the chamber, respectively. 


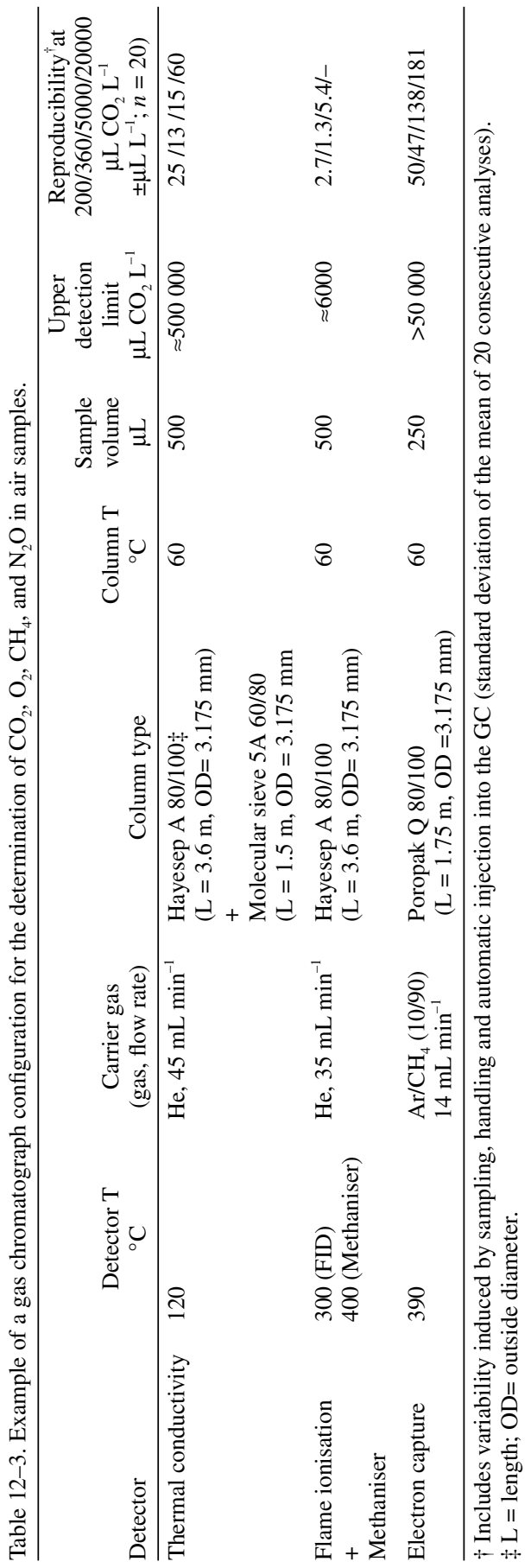


Flow-through steady-state chamber systems require accurate measurements of $f$ and $\left[\mathrm{CO}_{2}\right]$. Early prototypes of this chamber type employed a chemical trap to absorb $\mathrm{CO}_{2}$ from outgoing air, because accurate and portable $\mathrm{CO}_{2}$ analyzers were unavailable (Humfeld, 1930; Wallis \& Wilde, 1957). Unused absorbent (usually a $\mathrm{KOH}$ or $\mathrm{NaOH}$ solution) was then determined by titration. The $\left[\mathrm{CO}_{2}\right]$ of incoming air was assumed equal to the ambient level or estimated using a separate chemical trap to scrub air drawn from near the chamber inlet. Historically, the chamber system's flow control device was calibrated prior to deployment using a rotameter or 'bubble' flow meter and then assumed to maintain constant $f$ during the period of measurement. Correcting such measurements for changes in $T_{\mathrm{a}}$ and $P_{\mathrm{a}}$ was seldom done. Modern electronic mass flow meters provide continuous real-time $T_{\mathrm{a}}$ - and $P_{\mathrm{a}}$-corrected data, so they represent a much easier and more accurate alternative when electrical power is available. Nevertheless, rotameters remain the only method available at remote field sites and provide adequate data if they are calibrated carefully and read frequently along with the observations of $T_{\mathrm{a}}$ and $P_{\mathrm{a}}$ needed to correct the resulting data.

Early FT-SS chamber designs were also often plagued with technical problems that resulted from inadequate understanding of the factors controlling $F_{\mathrm{c}}$. For example, many $F_{\mathrm{c}}$ estimates were biased by pressure gradients induced by the air circulation system. In some systems, negative pressure was created by drawing air from a chamber having inadequate openings to compensate for the sampled air (Wallis \& Wilde, 1957). Other designs purposely maintained positive pressure inside the chamber to avoid contamination by ambient air (Reiners, 1968; Kucera \& Kirkham, 1971). Some authors recognized that pressure gradients created the potential for measurement error (Mina, 1962; Reiners, 1968; Kucera \& Kirkham, 1971), but Kanemasu et al. (1974) first quantified the error in detail. They showed that when air was drawn rather than pushed through a FT-SS chamber, $F_{\mathrm{c}}$ increased several fold even when the difference in headspace air pressure between these two modes of operation was $<4 \mathrm{~Pa}$. Later, Fang and Moncrieff (1996) established that the difference in pressure inside and outside the chamber should be $\leq 0.2 P_{\mathrm{a}}$ for reliable measurements. Recent FT-SS chamber designs incorporate elements that ensure negligible pressure gradients (Denmead, 1979; Rayment \& Jarvis, 1997; Fang \& Moncrieff, 1998).

Advantages of FT-SS compared with NSS chambers include the potential to maintain $\left[\mathrm{CO}_{2}\right]_{\mathrm{ch}}$ close to pre-deployment levels, better control of the temperature and humidity of both soil and air inside the chamber, and the possibility of near-continuous monitoring; however, exploiting these potential advantages in operational FT-SS systems is not easy, and sometimes not possible. For example, FT-SS chambers swept with a constant flow of ambient air cannot maintain $\left[\mathrm{CO}_{2}\right]_{\mathrm{ch}}$ equal to $\left[\mathrm{CO}_{2}\right]_{\mathrm{amb}}$. Instead, $\left[\mathrm{CO}_{2}\right]_{\mathrm{ch}}$ increases with time until it equals $C_{\mathrm{i}}+$ $F_{\mathrm{c}} \times(A M v / f)$. This concentration may be substantially larger than $\left[\mathrm{CO}_{2}\right]_{\mathrm{amb}}$, even at relatively large $f$ (Rayment, 2000). The time required to reach it varies widely and becomes longer with increasing chamber height and decreasing $f$. Achieving nearly constant $\mathrm{N}_{2} \mathrm{O}$ concentration in a FT-SS chamber has been reported to require as little as $2 \mathrm{~min}$ (Matthias et al., 1978) and as long as $60 \mathrm{~min}$ (Denmead, 1979). 
In a FT-SS chamber swept with zero air instead of ambient air, $\left[\mathrm{CO}_{2}\right]_{\mathrm{ch}}$ may either increase or decrease depending on $f$. For the special case where $F_{\mathrm{c}} \times A=$ $\left(f / M_{\mathrm{v}}\right) \times\left[\mathrm{CO}_{2}\right]_{\mathrm{amb}}$, there will be no change in $\left[\mathrm{CO}_{2}\right]_{\mathrm{ch}}$ following deployment and thus no chamber-induced error; however, only a small mismatch in the incoming and outgoing mass fluxes of $\mathrm{CO}_{2}$ is enough to spawn significant measurement errors (Hutchinson et al., 2000), so it is difficult to avoid such errors by adjusting $f$ in an attempt to achieve $\left[\mathrm{CO}_{2}\right]_{\mathrm{ch}}=\left[\mathrm{CO}_{2}\right]_{\mathrm{amb}}$. Real-time accurate measurements of both $\left[\mathrm{CO}_{2}\right]_{\mathrm{ch}}$ and $f$ are essential, because spatial variation in $F_{\mathrm{c}}$ is likely to require a different $f$ for every chamber placement. Moreover, the time required to attain nearly constant $\left[\mathrm{CO}_{2}\right]_{\mathrm{ch}}$ following each flow adjustment must be short compared to the temporal variability in $F_{\mathrm{c}}$. Even when practical considerations limit the success of attempts to match $\left[\mathrm{CO}_{2}\right]_{\mathrm{ch}}$ to $\left[\mathrm{CO}_{2}\right]_{\mathrm{amb}}$, minimizing the difference between these two concentrations remains a viable goal because leakage through imperfect chamber seals, lateral diffusion beneath the chamber walls, and other measurement errors vary with the size of this concentration difference (Hutchinson \& Livingston, 2001).

When $\left[\mathrm{CO}_{2}\right]_{\mathrm{ch}}$ is monitored in real time, users of FT-SS chambers often purposely base their flux estimates on the value measured when the rate of change in this concentration first approaches zero. Unfortunately, this also is the time of maximum deviation of $F_{\mathrm{c}}$ from the underlying true respiration rate (Hutchinson et al., 2000). After that time $\left[\mathrm{CO}_{2}\right]_{\mathrm{ch}}$ continues to change, although at a greatly reduced rate, as the $\left[\mathrm{CO}_{2}\right]$ in soil air adjusts to form a new gradient capable of again supporting $F_{\mathrm{c}}$ equal to soil respiration. This recovery from the initial nonsteady-state condition beneath a SS chamber does not occur rapidly enough to avoid measurement errors analogous to those for which NSS chambers are often criticized. Moreover, the magnitude of those errors varies with changes in soil and atmospheric parameters just as it does for NSS chambers. Modeling studies (Matthias et al., 1978; Hutchinson et al., 2000) suggest that the resulting bias in typical FT-SS estimates of soil respiration may be as high as $\pm 15 \%$ when the soil's air-filled porosity is 0.3 and $\pm 30 \%$ when air-filled porosity is 0.5 .

Despite their limitations, FT-SS chambers are more adaptable than NSS chambers to continuous monitoring of $F_{\mathrm{c}}$ during long periods (Rayment \& Jarvis, 1997). The convective transport of sensible and latent heat by the sweep air dissipates excess energy inside the chamber and helps maintain $T_{\mathrm{s}}$ close to outside conditions. Few articles report simultaneous measurements of $T_{\mathrm{s}}$ and $T_{\mathrm{a}}$ inside and outside FT-SS chambers. Soil temperature in the top $3 \mathrm{~cm}$ was lower during daytime and higher at night beneath a steel FT-SS chamber with a acrylic lid, but $\Delta T_{\text {s }}$ was always $\leq 2^{\circ} \mathrm{C}$ (Denmead, 1979). Similar results are presented for wind tunnels on bare soil and under canola residues in Fig. 12-4. These variations are much smaller than those reported by Matthias et al. (1980) for NSS chambers made of various materials. Other problems associated with long deployments can be reduced by equipping the FT-SS system with a retractable lid that is periodically closed for $F_{\mathrm{c}}$ measurement (McGinn et al., 1998). Correcting measured $\left[\mathrm{CO}_{2}\right]$ in FT-SS chambers for differences in $T_{\mathrm{a}}$ and $H_{\mathrm{a}}$ between ingoing and outgoing air is straightforward (Tables 12-1 and 12-2). These corrections are smaller for SS chambers than for NSS chambers. For example, the maximum correction for $H_{\mathrm{a}}$ at $20^{\circ} \mathrm{C}$ is $2.4 \%$ of the flux estimate. 


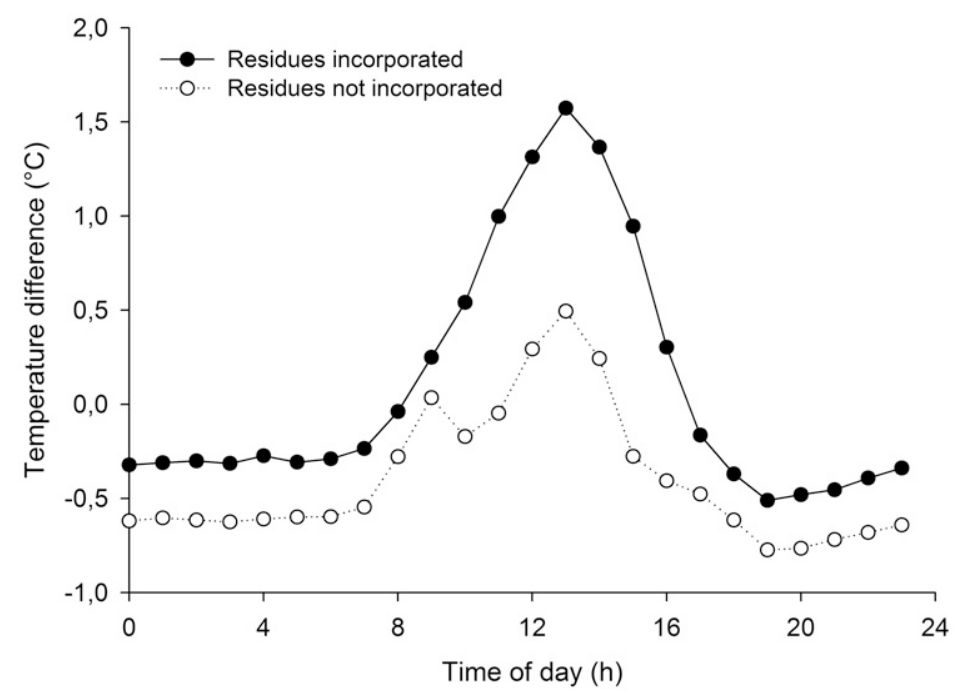

Fig. 12-4. Mean diurnal pattern of differences in soil temperature (1-cm depth) between outside and inside (Outside - Inside) of clear acrylic wind tunnels during 6 consecutive days. There were three tunnels for each treatment (Adapted from Rochette et al., 2001).

Minderman and Vulto (1973) and Freijer and Bouten (1991) proposed a FT-SS design in which headspace air was circulated at a known rate through an external $\mathrm{KOH}$ trap and then back to the chamber. Advantages include the avoidance of pressure gradients by using closed-loop air circulation and the opportunity to maintain $\left[\mathrm{CO}_{2}\right]_{\mathrm{ch}}$ close to $\left[\mathrm{CO}_{2}\right]_{\mathrm{amb}}$ without the requirement for an external source of zero air; however, the use of alkali is cumbersome, and as mentioned above, real-time accurate measurements of both $\left[\mathrm{CO}_{2}\right]_{\mathrm{ch}}$ and $f$ are essential for guiding efforts to minimize the difference between $\left[\mathrm{CO}_{2}\right]_{\mathrm{ch}}$ and $\left[\mathrm{CO}_{2}\right]_{\mathrm{amb}}$. Another example of an atypical FT-SS chamber is the wind tunnel (Lockyer, 1984), but it has rarely been used for measuring $F_{\mathrm{c}}$. Because it has large volume, large openings, and strong ventilation, a wind tunnel is expected to perturb existing environmental conditions only minimally. Nevertheless, Schwartzkopf (1978) observed a direct relationship between $F_{\mathrm{c}}$ and the air flow rate through the tunnel. More recently, a wind tunnel system was described (Iritz et al., 1997) and used (Morén \& Lindroth, 1999) for monitoring $F_{\mathrm{c}}$ under a forest canopy. Loubet et al. (1999) conducted an extensive theoretical and empirical validation of wind tunnels for measuring $F_{\mathrm{c}}$ and highlighted the importance of adequate air sampling to obtain an accurate measure of $C_{o}$. Wind tunnels may prove especially well adapted to measuring $F_{\mathrm{c}}$ from soil with large surface heterogeneity and air-filled macroporosity, as are found following tillage (Reicosky \& Lindstrom, 1993; Reicosky et al., 1997).

\section{Non-Flow-Through Steady-State Chambers}

Steady-state measurement of $F_{\mathrm{c}}$ at constant $\left[\mathrm{CO}_{2}\right]_{\mathrm{ch}}$ also can be achieved without air flow through the chamber. A NFT-SS chamber, variously labeled in 
the past as a static chamber, absorption chamber, or alkali trap chamber, has no air inlet or outlet. Instead, it contains a vessel that is supported above the soil surface and filled with a known amount of an alkali substance. Such chambers are typically deployed for long periods $(p)$, often 12 or $24 \mathrm{~h}$, and the amount of $\mathrm{CO}_{2}$ trapped by the alkali $\left(C_{\mathrm{a}} ; \mathrm{mol}\right)$ is determined by titration (Anderson, 1982) or by weight change for soda lime (Zibilske, 1994). $F_{\mathrm{c}}$ is calculated as follows:

$F_{\mathrm{c}}=\left(C_{\mathrm{a}}-C_{\mathrm{b}}\right) /(A p)$

where $A$ is the enclosed soil area and $C_{\mathrm{b}}(\mathrm{mol})$ is the amount of $\mathrm{CO}_{2}$ absorbed by an identical (blank) trap handled the same as other traps except that it has been placed in a chamber deployed over a non-emitting surface.

A NFT-SS chamber was the first device used for measuring soil respiration in situ (Bornemann, 1920; Lundegårdh, 1921), and the only one used very extensively before 1985 . Since that time, the development of accurate and portable $\mathrm{CO}_{2}$ analyzers has resulted in the progressive replacement of this chamber type by more sophisticated systems. The NFT-SS chamber is often described as inaccurate, either underestimating (Ewel et al., 1987; Norman et al., 1992; Rochette et al., 1992) or more seldom, overestimating (Bekku et al. 1997) $F_{\mathrm{c}}$ measured by FT-SS and NSS chambers. As a result, $F_{c}$ values obtained from NFT-SS chambers are considered by many as unreliable and, at best, estimates of the relative difference between sources (Minderman \& Vulto, 1973; Singh \& Gupta, 1977; Norman et al., 1997). This chamber technique, however, serves a need that is not addressed by other methods; i.e., it is a simple inexpensive means for obtaining multiple time-integrated measurements at remote locations. When used in combination with short-term measurements by other chamber techniques, NFT-SS chambers are useful tools for studying $F_{\mathrm{c}}$ in complex ecosystems where a large number of measurements is required (Janssens \& Ceulemans, 1998). In this section, we assess the current understanding of factors affecting the performance of NFT-SS chambers, then discuss how that knowledge should be used to guide their design and deployment protocol.

The rate of $\mathrm{CO}_{2}$ absorption by the alkali trap in a NFT-SS chamber is proportional to $\left[\mathrm{CO}_{2}\right]_{\mathrm{ch}}$. For a perfectly designed chamber the absorption rate is equal to $F_{\mathrm{c}}$ when $\left[\mathrm{CO}_{2}\right]_{\mathrm{ch}}=\left[\mathrm{CO}_{2}\right]_{\mathrm{amb}}$. In that situation there are no changes in $\left[\mathrm{CO}_{2}\right]$ either above or below the soil surface during the period of deployment, and $F_{\mathrm{c}}$ remains equal to the underlying rate of $\mathrm{CO}_{2}$ production. Achieving and maintaining this balance is difficult, if not impossible. Instead, $\left[\mathrm{CO}_{2}\right]_{\mathrm{ch}}$ often rises following chamber deployment until the rate of $\mathrm{CO}_{2}$ absorption becomes equal to $F_{\mathrm{c}}$. The result is a biased estimate of $F_{c}$ - first, because the increase in $\left[\mathrm{CO}_{2}\right]_{\mathrm{ch}}$ represents emitted $\mathrm{CO}_{2}$ not accounted for in the alkali trap, and secondly, because the elevated concentration supports $\mathrm{CO}_{2}$ losses by leakage through imperfect chamber seals and by lateral diffusion beneath the chamber walls. In contrast, $\left[\mathrm{CO}_{2}\right]_{\mathrm{ch}}$ may decline following chamber deployment if $F_{\mathrm{c}}$ is particularly small, or the ratio of alkali trap area to emitting soil surface area is too large. The result in this case is an overestimate (instead of underestimate) of $F_{c}$, because the decrease in $\left[\mathrm{CO}_{2}\right]_{\mathrm{ch}}$ represents absorbed $\mathrm{CO}_{2}$ not emitted from soil during the deployment period, and because the reduced concentration supports $\mathrm{CO}_{2}$ gain by the chamber system via leakage and subsurface lateral diffusion. 
Previous authors have studied many of the factors that influence the efficiency of $\mathrm{CO}_{2}$ absorption by an alkali trap. For example, under normal field conditions Gupta and Singh (1977) found that the rate of $\mathrm{CO}_{2}$ absorption was nearly six times greater by $1.25 M$ than $0.1 \mathrm{M} \mathrm{NaOH}$, and a linear relationship was observed between these two concentrations. Kirita and Hozumi (1966) concluded that a $\mathrm{KOH}$ concentration $>0.5 \mathrm{M}$ ensures an absorption rate $>90 \%$ of its theoretical value. Other reports indicate that the absorption rate varies little when the alkali concentration exceeds $0.2 M$ (Haber, 1958), $0.25 M$ (Minderman \& Vulto, 1973), or $0.5 M$ (Medina \& Zelwer, 1972). On the other hand, Douglas and Tedrow (1959) warned against using very high alkali concentrations, because of problems related to water vapor transfer from the soil to the alkali. Based on these results, it appears that the optimal alkali molarity is approximately 0.5 to 1.0. The absorption rate of such a solution was found to be insensitive to the amount of accumulated carbonate until its capacity had been reduced by 80 to 90\% (Haber, 1958), 73\% (Sharkov, 1984), 70\% (Stotzky, 1965), or 65\% (Gupta $\&$ Singh, 1977). To allow a margin for error we suggest using an alkali trap with total capacity approximately three times greater than the amount of $\mathrm{CO}_{2}$ expected to be emitted during the planned deployment period.

In addition to its dependence on volume and molarity the efficiency of $\mathrm{CO}_{2}$ absorption by the alkali solution has been reported to depend on the size and shape of its container (Sharkov, 1984), as well as the position of that container in the chamber headspace (Haber, 1958). Anderson (1982) recommended placing the trap $2 \mathrm{~cm}$ above the soil surface, while model calculations of Hutchinson and Rochette (2003) suggest that trap height has little effect unless it is so near the soil surface or the chamber top that the cross-sectional area available for $\mathrm{CO}_{2}$ transport is restricted. Size and shape of the alkali container has much greater importance, because it determines the ratio of exposed alkali surface area to emitting soil surface area (hereafter abbreviated as the alkali/chamber area ratio). Area ratios required to achieve optimal $\mathrm{CO}_{2}$ absorption rates were reported to be $13 \%$ by Kirita (1971) and $20 \%$ by Gupta and Singh (1977) for their respective chamber designs and deployment conditions. Nakadai et al. (1993) and Bekku et al. (1997) obtained greater trapping efficiency by soaking a sponge with $\mathrm{NaOH}$ solution to increase its area of contact between the air and the alkali. To maintain $\left[\mathrm{CO}_{2}\right]_{\mathrm{ch}}$ near $\left[\mathrm{CO}_{2}\right]_{\mathrm{amb}}$ when $F_{\mathrm{c}}=0.1$ or $0.2 \mathrm{mg} \mathrm{m}^{-2} \mathrm{~s}^{-1}$, Mina (1962) estimated that his NFT-SS system required area ratios of 14 and $28 \%$, respectively, which he calculated by dividing the expected $F_{\mathrm{c}}$ by the measured $\mathrm{CO}_{2}$ absorption rate of his $0.2 \mathrm{M} \mathrm{NaOH}$ trap when it was exposed to ambient air $\left(0.7 \mathrm{mg} \mathrm{m}^{-2} \mathrm{~s}^{-1}\right)$. In a comparison of NFT-SS systems with area ratios of 11.5 and 25\%, Sharkov (1984) found $48 \%$ less $\mathrm{CO}_{2}$ in the smaller trap after the first $3 \mathrm{~h}$ of deployment, but the difference was only $5 \%$ between the 12 th and 24 th $\mathrm{h}$. He concluded that in the chamber with the smaller trap, a larger fraction of the $\mathrm{CO}_{2}$ emitted early in the deployment period went into increasing $\left[\mathrm{CO}_{2}\right]_{\mathrm{ch}}$. Apparently, an area ratio near $20 \%$ provides good absorption efficiency in many situations, but this ratio can be altered when needed to keep $\left[\mathrm{CO}_{2}\right]_{\mathrm{ch}}$ as close as possible to $\left[\mathrm{CO}_{2}\right]_{\mathrm{amb}}$.

Despite decades of experience and scores of studies designed to optimize the design of NFT-SS chambers, many questions remain regarding their accuracy and performance, as well as the optimal protocol for their use. Most of these 
questions revolve around the limited $\mathrm{CO}_{2}$-absorbing efficiency of an alkali trap, which has often been noted but never fully explained. For example, Lieth and Ouellette (1962) found that complete absorption of $\left[\mathrm{CO}_{2}\right]_{\mathrm{amb}}$ in a sealed chamber required nearly $12 \mathrm{~h}$, and Friejer and Bouten (1991) reported that only $30 \%$ of the $\mathrm{CO}_{2}$ injected into a sealed chamber was absorbed after $150 \mathrm{~min}$. There is considerable textbook and empirical evidence that the transfer rate of gaseous $\mathrm{CO}_{2}$ from its subsurface point of production to the surface of an alkali trap in a NFT-SS chamber is much slower than its rate of dissolution and reaction with the alkali, and the weak dependence of $\mathrm{CO}_{2}$ absorption efficiency on alkali molarity greater than a modest threshold value (see above) supports this notion. To examine the consequences of this transport limitation, Hutchinson and Rochette (2003) used a numerical gas diffusion model to study its impact on the $\mathrm{CO}_{2}$ absorption efficiency of an alkali trap, as well as the processes governing $\mathrm{CO}_{2}$ gain or loss by the chamber system.

Results from a typical series of simulations are presented in Fig. 12-5, which illustrates the effect of changing the alkali/chamber area ratio when chamber walls were inserted to the impermeable bottom of the simulated domain 50 $\mathrm{cm}$ below the surface; other assumptions are listed at the top of the figure and explained briefly in its caption. Figure 12-5a shows the instantaneous simulated flux into the chamber $\left(F_{\mathrm{c}}\right)$ normalized with respect to the true unperturbed depthintegrated soil respiration rate $\left(F_{\mathrm{o}}\right)$ and plotted as a function of time after deployment. Figure 12-5b shows the normalized flux measured by the alkali trap over several deployment times of different length, while Fig. 12-5c gives the mean $\left[\mathrm{CO}_{2}\right]_{\mathrm{ch}}$ as a function of time. Under the assumed conditions, the traps with 30 and $40 \%$ alkali/chamber area ratios had initial absorption rates that nearly matched $F_{\mathrm{o}}$. There was, therefore, little change in $\left[\mathrm{CO}_{2}\right]_{\mathrm{ch}}, F_{\mathrm{c}}$ remained very near $F_{\mathrm{o}}$, and the amount of $\mathrm{CO}_{2}$ absorbed by the alkali provided a very good estimate of soil respiration for all deployment times ranging from $4 \mathrm{~h}$ to $24 \mathrm{~h}$. At smaller alkali/chamber area ratios the $\left[\mathrm{CO}_{2}\right]_{\mathrm{ch}}$ required to support a $\mathrm{CO}_{2}$ absorption rate approaching $F_{\mathrm{o}}$ became increasingly larger which, in turn, resulted in increasingly larger deviations of $F_{\mathrm{c}}$ and the alkali-measured flux from $F_{\mathrm{o}}$, especially early in the deployment period.

Note that despite the nearly seven-fold increase in $\left[\mathrm{CO}_{2}\right]_{\mathrm{ch}}$ when the alkali/chamber area ratio was only $5 \%$, maximum chamber-induced disturbance in $F_{\mathrm{c}}$ was comparatively small $(-16 \%)$ and decreased after $24 \mathrm{~h}$ to less than $-3 \%$ (Fig. 12-5a). Nevertheless, the alkali trap yielded a 38\% underestimate of $F_{\mathrm{o}}$ during the first 4-h period (Fig. 12-5b), because a substantial fraction of emitted $\mathrm{CO}_{2}$ remained in headspace air (Fig. 12-5c). When the deployment period was extended to $8 \mathrm{~h}$, the underestimate declined to $26 \%$, because of the declining rate of increase in the $\left[\mathrm{CO}_{2}\right]_{\mathrm{ch}}$ and the resulting return of the $F_{\mathrm{c}} / F_{\mathrm{o}}$ ratio toward unity. Further lengthening the deployment period resulted in better and better estimates of $F_{\mathrm{o}}$ by the alkali trap as effects of the initial non-steady-state condition were more and more diluted by absorption rates that more closely reflected the true soil respiration rate. In fact, alkali traps with all but the smallest area ratio yielded reasonably good estimates after $24 \mathrm{~h}$ deployment time; i.e., 0.944, 0.980, 0.992, and $0.997 \times F_{\mathrm{o}}$ for traps with alkali/chamber area ratios of $10,20,30$, and $40 \%$ respectively. 


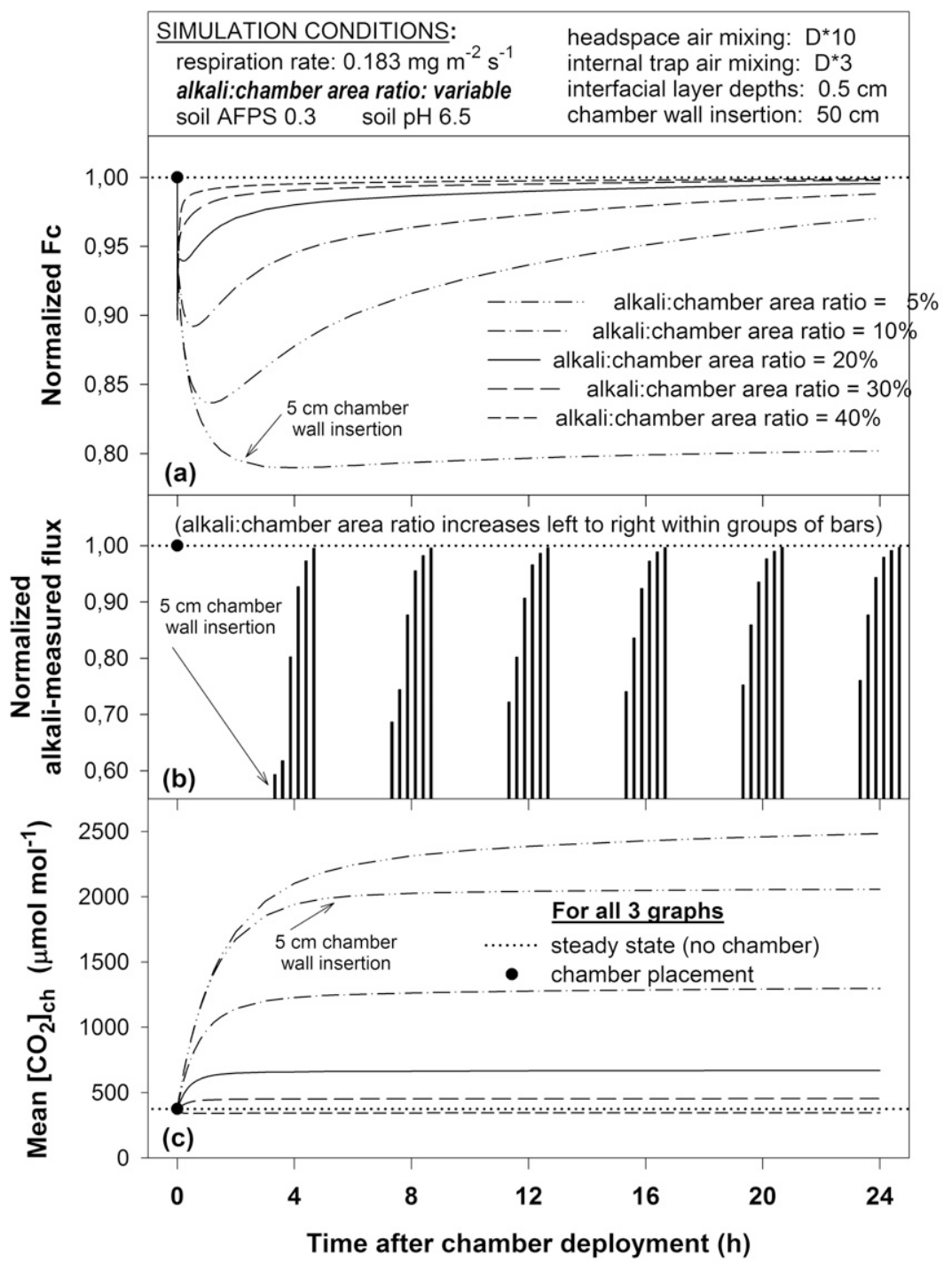

Fig. 12-5. Simulated effect of the ratio of exposed alkali surface area to emitting soil surface area on the performance of a NFT-SS chamber. Graph (a) shows the normalized instantaneous $\mathrm{CO}_{2}$ flux across the soil surface, graph (b) the cumulative amount of $\mathrm{CO}_{2}$ absorbed by the alkali trap, and graph (c) the headspace $\mathrm{CO}_{2}$ concentration all as a function of time under assumptions specified at the top of the figure (AFPS = soil air-filled pore space, and $\mathrm{D}=$ binary diffusion coefficient of $\mathrm{CO}_{2}$ in air). Chamber wall insertion depth was $50 \mathrm{~cm}$ except for the curves labeled differently. The fluxes in (a) and (b) were normalized with respect to the assumed depth-integrated rate of $\mathrm{CO}_{2}$ production (Adapted from Hutchinson \& Rochette, 2003). 
From other simulations Hutchinson and Rochette (2003) concluded that NFT-SS chambers should be non-vented. They reasoned that in a sealed chamber small amounts of headspace air will move upward and downward across the soil surface by mass flow in response to changes in $T_{\mathrm{a}}, P_{\mathrm{a}}$, etc., and the $\mathrm{CO}_{2}$ in that air will eventually be absorbed by the alkali trap rather than lost from the chamber system. Thus, there should be little, if any, net effect on NFT-SS chamber performance of perturbations that yield only short-term changes in chamber pressure, volume, or temperature, as long as the system is closed and the deployment period is long.

A disadvantage of the typically long deployment period of NFT-SS chamber systems is that net $\mathrm{CO}_{2}$ gain or loss via leakage through imperfect chamber seals and by lateral diffusion beneath the chamber walls may be larger and more difficult to control than for other chamber types. To compensate, chamber seals must be tight, and the chamber walls may need to be inserted to greater depth than for other chamber types. The potential importance of lateral diffusion is illustrated in Fig. 12-5, which includes results for a simulation identical to the one with 5\% area ratio described above except that chamber sidewalls were inserted only $5 \mathrm{~cm}$ into the soil. $\left[\mathrm{CO}_{2}\right]_{\mathrm{ch}}$ was not remarkably different in the two cases (2052 vs. 2483 $\mu \mathrm{mol} \mathrm{mol}{ }^{-1}$ after $24 \mathrm{~h}$ with 5 and $50 \mathrm{~cm}$ wall insertion, respectively), but the return of both $F_{\mathrm{c}}$ and the alkali-measured flux toward their pre-deployment rates was substantially impeded by the loss of $\mathrm{CO}_{2}$ via lateral diffusion beneath the chamber walls. Such $\mathrm{CO}_{2}$ loss (gain) by a NFT-SS chamber system, as well as the measurement error attributable to depletion or accumulation of the gas within and beneath it, become more problematic with increasing departure of $\left[\mathrm{CO}_{2}\right]_{\mathrm{ch}}$ from $\left[\mathrm{CO}_{2}\right]_{\mathrm{amb}}$, thus emphasizing that the alkali trap should be designed such that its $\mathrm{CO}_{2}$ absorption rate at $\left[\mathrm{CO}_{2}\right]_{\mathrm{amb}}$ matches $F_{\mathrm{o}}$ as closely as possible.

Finally, the typically long deployment periods of NFT-SS chambers also make it virtually impossible to maintain small $\Delta T_{\mathrm{s}}$. Under clear skies, users should expect differences of several degrees $C$, which probably alters the subsurface rates of plant and microbial respiration that the chamber was intended to measure. Opaque chambers in which $T_{\mathrm{s}}$ is lower than outside values during daytime experience the opposite trend at night (Sharkov, 1984), so 24-h deployments may reduce the $T_{\mathrm{s}}$ bias in soil respiration measurements. Deployments longer than $24 \mathrm{~h}$ are discouraged to avoid problems related to modified soil water content. Microbial respiration also is sensitive to $\left[\mathrm{CO}_{2}\right]$ (MacFayden, 1973; Bekku et al., 1997) and [O $\left.\mathrm{O}_{2}\right]$ (Parr \& Reuszer, 1959; van Cleve et al., 1979; Sharkov, 1984). Simple calculations indicate that $\left[\mathrm{O}_{2}\right]$ in a typical chamber should decrease by only $0.035 \mathrm{~m}^{3} \mathrm{~m}^{-3} \mathrm{~d}^{-1}\left(0.2 \mathrm{~m}\right.$ chamber height, $0.2 \mathrm{~m}$ soil depth, $19 \%$ [O $\left.\mathrm{O}_{2}\right], 0.25 \mathrm{~m}^{3}$ $\mathrm{m}^{-3}$ air-filled porosity, $0.17 \mathrm{mg} \mathrm{m}^{-2} \mathrm{~s}^{-1}$ respiration rate, respiration ratio of 1$)$. This rate of $\left[\mathrm{O}_{2}\right]$ decline should have no effect on the soil respiration rate for at least 2 $\mathrm{d}$, if the threshold for such effects is $0.14 \mathrm{~m}^{3} \mathrm{~m}^{-3}$ as proposed by Greenwood (1961) and Glinski and Stępniewski (1985).

In summary, we recommend:

1. To construct the chamber from materials that minimize $\Delta T_{\mathrm{s}}$ for the conditions of the study (Matthias \& Peralta-Hernãndez, 1998).

2. To use a non-vented chamber design that minimizes the exchange of enclosed air with ambient air in response to changes in $T_{\mathrm{a}}$ and $P_{\mathrm{a}}$. 
3. To provide good seals between chamber components and deep collar insertion to minimize $\mathrm{CO}_{2}$ gain or loss by leakage or lateral diffusion beneath chamber walls.

4. To use an alkali solution with molarity between 0.5 and 1.0 and capacity about three times greater than the amount of $\mathrm{CO}_{2}$ expected to be emitted during the deployment period.

5. To perform measurements during at least $12 \mathrm{~h}$ and preferably $24 \mathrm{~h}$ to reduce mean $\Delta T_{\mathrm{s}}$, as well as measurement bias due to the initial nonsteady-state condition.

6. To design the alkali trap such that $\left[\mathrm{CO}_{2}\right]_{\mathrm{ch}}$ remains as close as possible to $\left[\mathrm{CO}_{2}\right]_{\mathrm{amb}}$.

7. To test the absorption efficiency of the alkali trap during exposure to non-turbulent air at $\left[\mathrm{CO}_{2}\right]_{\mathrm{amb}}$, and to measure $\left[\mathrm{CO}_{2}\right]$ at or near the end of the deployment period (Mina, 1962).

\section{Non-Steady-State Chambers}

Non-steady-state chambers also have been designated as closed or static chambers and as the enrichment method. In contrast to SS chambers, emitted $\mathrm{CO}_{2}$ accumulates in NSS chambers throughout deployment, and their estimate of $F_{\mathrm{c}}$ depends on determining that rate of accumulation $\left(\partial C / \partial t ; \mu \mathrm{mol} \mathrm{mol} \mathrm{m}^{-1} \mathrm{~s}^{-1}\right)$. The estimate is calculated using:

$F_{\mathrm{c}}=\partial C / \partial t(V / A) / M v$

where $V\left(\mathrm{~m}^{3}\right)$ is the chamber volume and $M_{\mathrm{v}}$ is determined at chamber air temperature.

Because an increase in $\left[\mathrm{CO}_{2}\right]_{\mathrm{ch}}$ has an immediate impact on the rate of $\mathrm{CO}_{2}$ emission at the soil surface (see previous section), the value of $F_{\mathrm{c}}$ obtained from this equation is an underestimate of the soil respiration rate that the NSS chamber was intended to measure. Furthermore, with increasing deployment time the $\mathrm{CO}_{2}$ concentration of a larger and larger volume of soil air is subject to alteration, leading to a progressive decline in $F_{\mathrm{c}}$. This pattern has been predicted by models (Healy et al., 1996) and observed under field conditions (Fig. 12-3) (Makarov, 1959; Naganawa \& Kyuma, 1991; Rochette et al., 1997). Rayment (2000) described the interdependence of the soil $\left[\mathrm{CO}_{2}\right]$ profile and $\partial C / \partial t$ in terms of an increase in effective chamber volume during deployment. The key to minimizing this bias and obtaining more accurate estimates of soil respiration using NSS chambers is to use the measured values of $\left[\mathrm{CO}_{2}\right]_{\mathrm{ch}}$ to project a $\partial C / \partial t$ representative of the pre-deployment soil $\left[\mathrm{CO}_{2}\right]$ profile.

Several strategies have been proposed for minimizing bias in the measured value of $\partial C / \partial t$ within a NSS chamber. The most common is to estimate $\partial C / \partial t$ as early as possible during deployment. Usually, a simple mathematical model is used to describe the time-dependence of changes in $\left[\mathrm{CO}_{2}\right]_{\mathrm{ch}}$, and $\partial C / \partial t$ is estimated from the slope of that curve extrapolated to the moment of chamber deployment. Linear regression is often chosen for this purpose because of its simplicity, and because it accommodates measurement variability and is easily adaptable to significance testing. It is important to realize, however, that choosing 
this model may itself introduce bias, because the basic laws of time-dependent diffusion dictate that the accumulation of $\mathrm{CO}_{2}$ within a NSS chamber must be nonlinear (Matthias et al., 1978; Healy et al., 1996; Hutchinson \& Livingston, 2001). Certainly, existing literature contains many examples of data for which a plot of $\left[\mathrm{CO}_{2}\right]_{\mathrm{ch}}$ vs. time appears to be linear, but these represent situations for which the inherent curvature is simply too small to detect via linear regression that is necessarily flawed by serial correlation in the data (Pedersen, 2000; Pedersen et al., 2001). Non-linear (quadratic, cubic, exponential) models often yield less-biased estimates of $\partial C / \partial t$, but may exhibit extreme sensitivity to measurement imprecision (Hutchinson \& Mosier, 1981; Anthony et al., 1995; Pedersen, 2000; Pedersen et al., 2001). As a result, the best choice of a model for estimating $\partial C / \partial t$ must be a compromise that depends on the deployment duration, as well as the number and frequency of $\left[\mathrm{CO}_{2}\right]_{\mathrm{ch}}$ measurements, all of which are influenced by whether a portable $\mathrm{CO}_{2}$ analyzer is used (FT-NSS) or not (NFT-NSS).

The design and principles of operation of NFT-NSS chambers have been thoroughly reviewed in recent years (Livingston \& Hutchinson, 1995; Hutchinson \& Livingston, 2002), and much of that information applies to FT-NSS chambers as well. Summarizing briefly, any change resulting in smaller effective $\mathrm{CO}_{2}$ diffusivity decreases the potential for chamber-induced measurement error (including the inherent bias in estimating $\partial C / \partial t$ ). As a result, chamber performance is better in fine-textured compared with sandy soil, in compacted compared with non-compacted soil, in wet compared with dry soil, and in uniform compared with non-uniform soil with vertically aligned fractures, earthworm holes, etc. Performance also is improved when the gas of interest has a small storage coefficient (i.e., low water solubility and small tendency for rapidly reversible surface adsorption), but it degrades rapidly as the storage coefficient increases. Finally, the potential for chamber-induced measurement error is essentially independent of the magnitude, kinetics, and/or distribution of the $\mathrm{CO}_{2}$ source. Users of NSS chambers must remain aware of all these potential sources of measurement error and be prepared to make compensating adjustments in deployment time, chamber wall insertion depth, chamber height, etc., especially when the effective $\mathrm{CO}_{2}$ diffusivity is large. Rationale and guidelines for making such adjustments are discussed in detail in the reviews cited above. Because those reviews are recent and thorough, we offer here only a few brief comments specific to the measurement of soil respiration using NFT-SS and FT-NSS chambers.

\section{Non-Flow-Through}

Soil-surface $\mathrm{CO}_{2}$ fluxes have been measured using NFT-NSS chambers (Lundegårdh, 1926; Makarov, 1959; Gupta \& Singh, 1977; Parkinson, 1981), but this technique is more commonly adopted for measuring the fluxes of other gases including $\mathrm{N}_{2} \mathrm{O}$ (Matthias et al., 1980; Mosier \& Hutchinson, 1981) and $\mathrm{CH}_{4}$ (Crill, 1991; Striegl et al., 1992). This chamber type is not easily automated, so few such systems have been proposed (Scott et al., 1999). In the absence of an on-site gas analyzer, $\left[\mathrm{CO}_{2}\right]_{\mathrm{ch}}$ must be measured in a minimum of three, but preferably four or more, discrete air samples taken at regular intervals during the deployment period and then transported to the laboratory for analysis. The analysis can be performed with an IRGA (Parkinson, 1981; Bekku et al., 1995), but is 
more often accomplished by gas chromatography (see previous section). To minimize the bias described above, we recommend using a non-linear model to estimate $\partial C / \partial t$ from these measurements, but realize that this approach may fail to fully account for the rapid initial changes in $F_{\mathrm{c}}$ that occur shortly after chamber placement. For example, Healy et al. (1996) predicted 13\% underestimation of $F_{\mathrm{c}}$ by a diffusion-based non-linear model applied to data from a perfectly mixed NFT-NSS chamber deployed for 30 min on dry soil.

It is often argued that thermal buoyancy and/or external turbulence-induced pressure fluctuations generally support uniform mixing in the headspace of a NFT-NSS chamber; however, the large temporal variability in $\partial C / \partial t$ measured in air-flow-mixed FT-NSS chambers reported in Fig. 12-3 suggests that NFT-NSS chamber users should sometimes consider using a fan. The decision to employ forced head space mixing must be made carefully, because modeling studies indicate that it may artificially enhance $\mathrm{CO}_{2}$ exchange rates when pre-deployment mixing is poor, such as within a dense vegetation canopy on a calm cloudy day (Hutchinson et al., 2000).

The deployment period for a NFT-NSS chamber should be as short as possible, but long enough to allow a measurable increase in $\left[\mathrm{CO}_{2}\right]_{\mathrm{ch}}$ between consecutive sampling times. The minimum duration decreases with increasing $F_{\mathrm{c}}$, analytical precision and air mixing intensity, but increases with the chamber volume/area ratio. Based on the performance of the flame ionization detector described in Table 12-3, the minimum deployment period of a well-mixed midsize NFT-NSS chamber (volume, $60 \mathrm{~L}$; cross-section, $0.3 \mathrm{~m}^{2}$; height, $0.2 \mathrm{~m} ; F_{\mathrm{c}}$, $0.1 \mathrm{mg} \mathrm{m}^{-2} \mathrm{~s}^{-1}$ ) would be approximately $20 \mathrm{~s}$ if four samples were taken; however, NFT-NSS deployment periods are typically much longer for various reasons, including to allow enough time for rotational sampling of several chambers deployed simultaneously, to compensate for imperfect chamber mixing and to permit measurable accumulation of other gases that are often determined in the same air samples (Kessavalou et al., 1998). Such benefits of longer deployment periods must be weighed against the risk of increasing the underestimation of $F_{\mathrm{c}}$ (Healy et al., 1996). We strongly recommend against using deployment periods longer than $1 \mathrm{~h}$ to avoid large changes in $T_{\mathrm{a}}$ and $T_{\mathrm{s}}$, and to focus the sampling effort on early times that are likely to best characterize the initial value of $\partial C / \partial t$.

Corrections in the measured values of $\left[\mathrm{CO}_{2}\right]_{\mathrm{ch}}$ are required to account for the effect of $T_{\mathrm{a}}$ and $H_{\mathrm{a}}$ variations during deployment. Equilibrating air samples at room temperature and successive analysis of all samples from a given chamber deployment will automatically correct for density variations associated with $T_{\mathrm{a}}$ variations (Table 12-1). Because humidity is not usually measured in individual NFT-NSS chamber air samples, we recommend drying the air samples prior to analysis to account for dilution effects. Drying of air samples in pressurized glass vials can be achieved by placing a desiccant such as magnesium perchlorate ${ }^{1}(\mathrm{Mg}$ $\left.\left(\mathrm{ClO}_{4}\right)_{2}\right)$ in the vials prior to their evacuation (3 $\mathrm{mg}$ per $12-\mathrm{mL}$ vial at $200 \mathrm{kPa}$ ). The resulting overestimation of the $\mathrm{CO}_{2}$ mole fraction can be corrected as indi-

\footnotetext{
${ }^{1}$ Magnesium perchlorate is a strong oxidizing agent. Contact with skin or mucus membranes may cause irritation. Avoid bringing into contact with acids and organic substances such as cotton, rubber, grain dust, etc. Consult the container label.
} 
cated in Table 12-2, if the mean chamber $H_{\mathrm{a}}$ is known. The latter value can be measured on site using inexpensive handheld sensors or estimated from weather data and adjusted by the user according to the soil climatic conditions at the experimental site. Approximate values of $H_{\mathrm{a}}$ are adequate, because this correction is relatively small; for example, at $20^{\circ} \mathrm{C}$ the maximum correction would be $1.2 \%$ of the $\mathrm{CO}_{2}$ flux if $\mathrm{H}_{\mathrm{a}}$ corresponding to $50 \% \mathrm{RH}$ is assumed.

\section{Flow-Through}

Compared with a NFT-NSS chamber, the nearly continuous monitoring of $\left[\mathrm{CO}_{2}\right]_{\mathrm{ch}}$ by the on-site analyzer used in a FT-NSS chamber provides a more detailed description of the pattern of $\mathrm{CO}_{2}$ accumulation. The greater number and frequency of $\left[\mathrm{CO}_{2}\right]_{\mathrm{ch}}$ measurements also facilitates using a shorter deployment period. Other advantages include early detection of experimental problems that would ultimately require the resulting data to be discarded, fewer problems related to leakage and lateral diffusion beneath the chamber walls, and smaller changes in air and soil temperature and humidity. Because of this powerful set of advantages, this chamber type has recently experienced widespread adoption. In fact, several commercial FT-NSS chamber systems for measuring soil respiration have appeared within the last decade (e.g., Li-Cor Inc., Lincoln, NE; PP-Systems, Hitchin, England; BioScientific, Ltd., Hoddesdon, England; CID Inc., Camas, WA). Both commercial and custom FT-NSS chamber systems can be adapted for near-continuous monitoring of $F_{\mathrm{c}}$ over daily, weekly, or even seasonal and annual time periods (Loftfield et al., 1992; Goulden \& Crill, 1997; Ambus \& Robertson, 1998).

Disadvantages of this chamber type include that the short deployment periods seldom allow for the simultaneous measurement of other gases like $\mathrm{N}_{2} \mathrm{O}$ and $\mathrm{CH}_{4}$, and they focus the sampling effort on the period most likely to exhibit the influence of soil disturbance, changes in the air mixing regime at the soil surface, pressure effects, etc. Accordingly, we strongly recommend that the whole time series of $\left[\mathrm{CO}_{2}\right]_{\mathrm{ch}}$ measurements be stored for subsequent analysis and quality assessment. All systems, whether commercial or custom, also should be tested for leaks by sealing the chamber to a non-emitting surface (with the analyzer pump running) and then blowing air with elevated $\left[\mathrm{CO}_{2}\right]$ onto all tubing, connections, seals and joints. The internal tubing (including the pump) must be leaktested to avoid inducing negative or positive pressure disturbances and their associated effects on $F_{\mathrm{c}}$ determination. Finally, the greater sampling efficiency of this chamber type depends on adequate mixing of the chamber headspace; although mixing generated by sample air flowing through the analyzer is usually sufficient in small chambers, larger chambers may require use of an auxiliary fan.

Three approaches have been used for estimating $\partial C / \partial t$ at the moment of deployment of a FT-NSS chamber. The first is identical to that described for a NFT-NSS chamber, but should yield better results in this case because of the greater number of measurements during a typically shorter deployment period. For example, simulation studies reported by Healy et al. (1996) suggest that decreasing the length of the deployment period from $30 \mathrm{~min}$ to $1 \mathrm{~min}$ reduced the underestimation of gas flux from soil with $30 \%$ air-filled porosity from 7.6 to 
$1.7 \%$; however, we recommend against using periods shorter than $5 \mathrm{~min}$ to facilitate detecting deployments when $F_{\mathrm{c}}$ has been significantly influenced by site disturbance. Abrupt changes in $\partial C / \partial t$ or strong non-linearity can occur during the first 2 min of the deployment period as a result of chamber perturbations other than the feedback effects of increasing $\left[\mathrm{CO}_{2}\right]_{\mathrm{ch}}$ on the $\left[\mathrm{CO}_{2}\right]$ profile. When $\partial C / \partial t$ does not remain nearly constant or decrease with time as predicted by the diffusion theory (Healy et al., 1996), the data should be rejected.

A second approach that has been used for estimating $\partial C / \partial t$ at the moment of FT-NSS chamber deployment is to first reduce $\left[\mathrm{CO}_{2}\right]_{\mathrm{ch}}$ below $\left[\mathrm{CO}_{2}\right]_{\mathrm{amb}}$ and then record $\partial C / \partial t$ when $\left[\mathrm{CO}_{2}\right]_{\mathrm{ch}}$ again reaches its pre-deployment level (Norman et al., 1992). Reduction of $\left[\mathrm{CO}_{2}\right]_{\mathrm{ch}}$ can be achieved by passing sampled air through a chemical trap (soda lime) before returning it to the chamber. This approach purportedly eliminates feedback effects of $\left[\mathrm{CO}_{2}\right]_{\mathrm{ch}}$ on $F_{\mathrm{c}}$ and permits rapid measurements $(\approx 2 \mathrm{~min})$; however, it is only applicable to relatively small chambers because reducing $\left[\mathrm{CO}_{2}\right]_{\mathrm{ch}}$ requires that $\left[\mathrm{CO}_{2}\right]_{\mathrm{ch}} \times$ flow rate through the trap $>F_{\mathrm{c}} \times$ $A$. Readers also are cautioned that the potential impacts of rapid fluctuations in $\left[\mathrm{CO}_{2}\right]_{\mathrm{ch}}$ on $\mathrm{CO}_{2}$ diffusion, and thus $F_{\mathrm{c}}$, have not been fully investigated.

The third approach for estimating $\partial C / \partial t$ in a FT-NSS chamber is a special case of the first. It assumes linearity in a plot $\left[\mathrm{CO}_{2}\right]_{\mathrm{ch}}$ vs. time across some preselected fraction of the deployment period (usually 0.5 to $2 \mathrm{~min}$ ) and uses the mean slope over that period to estimate $\partial C / \partial t$. Field tests suggest that across short deployments, a linear fit is probably the best estimator of $\partial C / \partial t$ because of the greater sensitivity of non-linear models to measurement imprecision and to site disturbance effects (Rochette, data not shown). The smaller data set obtained using this approach may sacrifice accuracy compared with the other two, but a larger number of measurements can be performed in any given period of time.

Corrections are required to account for the effect of $T_{\mathrm{a}}$ and $H_{\mathrm{a}}$ variations on the measured values of $\left[\mathrm{CO}_{2}\right]_{\mathrm{ch}}$. Built-in functions in most commercial analyzers automatically correct for density variations associated with $T_{\mathrm{a}}$ variations (Table $12-1$ ); if not, the ideal gas law or empirical corrections must be employed. Some commercial soil respiration systems also account for the effects of variations in $H_{\mathrm{a}}$ on the calculation of $F_{\mathrm{c}}$ (LI-6400 and 6200, Li-Cor Inc., Lincoln, NE). Otherwise, one of the schemes described in Table 12-2 must be employed, depending on whether the sample air is dried prior to analysis.

\section{INTERCOMPARISON BETWEEN SYSTEMS}

Lack of information regarding the accuracy of various measuring techniques makes it difficult to compare $F_{\mathrm{c}}$ estimates among studies in which different techniques were used. Under field conditions the true $F_{\mathrm{c}}$ is unknown, so it is impossible to validate flux measurements obtained by any technique. As an alternative, laboratory studies have been conducted in which the performance of several chamber types was compared against a known $\mathrm{CO}_{2}$ source. Bekku et al. (1997) compared four chamber methods against $F_{\mathrm{c}}$ calculated from the amount of glucose used by decomposers in an artificial medium sealed (no leaks) in an enclosure. They found excellent agreement of FT-SS, FT-NSS, and NFT-NSS 
chambers with the reference $F_{\mathrm{c}}$ and suggested that low $\left[\mathrm{CO}_{2}\right]_{\mathrm{ch}}\left(200 \mu \mathrm{mol} \mathrm{mol}{ }^{-1}\right)$ was a possible cause for $30 \%$ overestimation by the NFT-SS chamber. Nay et al. (1994) controlled $\left[\mathrm{CO}_{2}\right]$ under an 18-cm layer of polyurethane foam and calculated $\mathrm{CO}_{2}$ flux through the foam using Fick's law of diffusion. Their NFT-SS chamber (24-h deployment) overestimated low $F_{\mathrm{c}}$ and underestimated high Fc, probably because of lateral $\mathrm{CO}_{2}$ diffusion beneath chamber walls inserted only $2.5 \mathrm{~cm}$ into the foam. Their FT-NSS chamber (78-s deployment period; linear fit of $\left[\mathrm{CO}_{2}\right]_{\mathrm{ch}}$ vs. time) underestimated $F_{\mathrm{c}}$ by $15 \%$ at all $F_{\mathrm{c}}$. Widén and Lindroth (2003) recently described a chamber calibration system with the advantage that its surface $\mathrm{CO}_{2}$ efflux rate can be determined directly, but their comparison of chamber types was confounded by inability to always maintain zero pressure difference across the system's 5-cm layer of quartz sand.

In addition to laboratory studies, several experiments have compared the performance of different chamber types for measuring $F_{\mathrm{c}}$ under field conditions. Of the studies listed in Table 12-4 about half involved comparing the older NFTSS technique with either a FT-NSS or FT-SS chamber. For this group, the NFTSS chamber estimate of $F_{\mathrm{c}}$ averaged $19 \%$ smaller $(\mathrm{sd}=46 \%)$. The high variability resulted largely from overestimation at low $F_{\mathrm{c}}$ and underestimation at high $F_{\mathrm{c}}$ by the NFT-SS chamber, which is in agreement with the effects of $\left[\mathrm{CO}_{2}\right]_{\mathrm{ch}}$ observed by Nay et al. (1994). Two commercially available FT-NSS chamber systems also have been compared in the field. In two independent studies, $F_{\mathrm{c}}$ obtained using the SRC-1 chamber (PP Systems, England) was 1.49 (Le Dantec et al., 1999) or 1.85 (Janssens et al., 2000) times greater than that measured by the LI-6200 equipped with a 6000-09 chamber (LI-COR Inc., Lincoln, NE). Both groups of authors attributed the disparity to differences in headspace air mixing intensity.

Comparisons between chamber and micrometeorological techniques are complicated by many factors, including the impossibility of simultaneously sampling the same source area (due to contamination of the micrometeorological source by the chamber operator), the large spatial variability of chamber measurements, and the uncertainties associated with required air density corrections to the micrometeorological estimates, which are often larger than $F_{\mathrm{c}}$. Nevertheless, all comparisons of FT-NSS chambers with micrometeorological techniques showed reasonable agreement.

We compared FT-NSS and NFT-NSS chambers using 247 paired measurements made during June and July 2000 (23 sampling days) following the application of pig slurry (variable dosage on 12 plots with fine-textured soil kept free of vegetation). The slurry resulted in uncommonly high $F_{\mathrm{c}}$, which allowed comparisons across a wide range of fluxes $\left(0.05\right.$ to $\left.2.5 \mathrm{mg} \mathrm{m}^{-2} \mathrm{~s}^{-1}\right)$. The two techniques were compared as they are routinely used: 60-min deployment time for the NFT chamber, which was sampled after 0, 20, 40, and $60 \mathrm{~min}$, vs. 2-min deployment time for the FT chamber with $\left[\mathrm{CO}_{2}\right]_{\mathrm{ch}}$ measured every $1.5 \mathrm{~s}$. Rate of change of $\left[\mathrm{CO}_{2}\right]_{\mathrm{ch}}(\partial C / \partial t)$ was determined using a quadratic equation for the NFT system and by a linear equation for the FT system. The FT system (described earlier) was operated with one fan running. The NFT system was identical except it was not fan-mixed. For each comparison, $F_{\mathrm{c}}$ was measured first using the FT chamber; NFT chamber measurements followed about $1 \mathrm{~h}$ later. There was a lin- 
Table 12-4. Intercomparisons of soil-surface $\mathrm{CO}_{2}$ flux estimates between several chamber and micrometeorological techniques $($ FT $=$ Flow-Through; NFT $=$ Non-FT; $S S=$ Steady-State; NSS = Non-SS).

\begin{tabular}{lll}
\hline NFT-NSS vs. FT-NSS & & \\
\hline NFT-NSS/FT-NSS & Reference & Comments \\
$0.69 ; 0.77$ & Norman et al., 1997 & $\begin{array}{l}\text { NFT-NSS: linear interpolation between } \\
{\left[\mathrm{CO}_{2}\right] \text { ch at } 0 \text { and } 10 \text { min following }} \\
\text { deployment }\end{array}$ \\
& &
\end{tabular}

Rochette (unpublished data, 2001)

See Fig. 12-5

Average $=0.79 \pm 0.11$

NFT-NSS vs. NFT-SS

\begin{tabular}{lll}
\hline NFT-NSS/NFT-SS & Reference & Comments \\
\hline 1 & Raich et al., 1990 & $\begin{array}{l}\text { Poor correlation between the two } \\
\text { chambers }\end{array}$ \\
\hline
\end{tabular}

NFT-NSS vs FT-SS

\begin{tabular}{lll}
\hline NFT-NSS/FT-SS & Reference & Comments \\
\hline & & No comparison found in the literature \\
\hline
\end{tabular}

\section{NFT-SS vs. FT-SS}

\begin{tabular}{lll}
\hline NFT-SS/FT-SS & Reference & Comments \\
\hline $1.0 @ 0.06 \mathrm{mg} \mathrm{m}^{-2} \mathrm{~s}^{-1}$ & Ewel et al., 1987 & Alkali trap = soda lime \\
$0.5 @ 0.24 \mathrm{mg} \mathrm{m}^{-2} \mathrm{~s}^{-1}$ & & Kuc
\end{tabular}

$\begin{array}{lll}0.61 & \text { Kucera and Kirkham, } 1971 & \text { Alkali trap }=\mathrm{KOH} \\ 2 & \text { Nakadai et al., } 1993 & \begin{array}{l}\text { Alkali trap }=\mathrm{KOH} \text { in soaked sponge } \\ \text { maintained low }\left[\mathrm{CO}_{2}\right] \mathrm{ch}\end{array}\end{array}$

$1.0 @ 0.05 \mathrm{mg} \mathrm{m}^{-2} \mathrm{~s}^{-1} \quad$ Cropper et al., 1985

Alkali trap= soda lime; same techniques

$0.5 @ 0.22 \mathrm{mg} \mathrm{m}^{-2} \mathrm{~s}^{-1}$ as Ewel et al., 1987

Average $=0.94 \pm 0.57$

\begin{tabular}{|c|c|c|}
\hline \multicolumn{3}{|l|}{ NFT-SS vs FT-NSS } \\
\hline NFT-SS/FT-NSS & Reference & Comments \\
\hline 1.83 & Janssens et al., 2000 & $\begin{array}{l}\text { Alkali trap = soda lime maintained low } \\
{\left[\mathrm{CO}_{2}\right] \text { ch; used LI-COR chamber as }} \\
\text { reference }\end{array}$ \\
\hline $\begin{array}{l}1.0 @ 0.03 \mathrm{mg} \mathrm{m}^{-2} \mathrm{~s}^{-1} \\
0.66 @ 0.26 \mathrm{mg} \mathrm{m}^{-2} \mathrm{~s}^{-1}\end{array}$ & $\begin{array}{l}\text { Janssens and Ceulemans, } \\
1998\end{array}$ & $\begin{array}{l}\text { Alkali trap = soda lime; used PP Systems } \\
\text { chamber as reference }\end{array}$ \\
\hline $\begin{array}{l}0.67 @ 0.06 \mathrm{mg} \mathrm{m}^{-2} \mathrm{~s}^{-1} \\
0.3 @ 0.22 \mathrm{mg} \mathrm{m}^{-2} \mathrm{~s}^{-1}\end{array}$ & Norman et al., 1992 & $\begin{array}{l}\text { Alkali trap }=\mathrm{KOH} \text {; used LI-COR } \\
\text { prototype chamber as reference }\end{array}$ \\
\hline $\begin{array}{l}0.75 @ 0.12 \mathrm{mg} \mathrm{m}^{-2} \mathrm{~s}^{-1} \\
0.61 @ 0.15 \mathrm{mg} \mathrm{m}^{-2} \mathrm{~s}^{-1}\end{array}$ & Rochette et al., 1992 & $\begin{array}{l}\text { Alkali trap }=\mathrm{NaOH} \text {; used custom FT-NSS } \\
\text { as reference }\end{array}$ \\
\hline 0.9 to 1.1 & Rochette et al., 1997 & $\begin{array}{l}\text { Alkali trap }=\mathrm{NaOH} \text {; used custom FT-NSS } \\
\text { as reference; several comparisons }\end{array}$ \\
\hline $\begin{array}{l}0.8 @ 0.09 \mathrm{mg} \mathrm{m}^{-2} \mathrm{~s}^{-1} \\
0.5 @ 0.22 \mathrm{mg} \mathrm{m}^{-2} \mathrm{~s}^{-1}\end{array}$ & Haynes and Gower, 1995 & $\begin{array}{l}\text { Alkali trap = soda lime; used LI-COR } \\
\text { chamber as reference }\end{array}$ \\
\hline $\begin{array}{l}0.4 @ 0.07 \mathrm{mg} \mathrm{m}^{-2} \mathrm{~s}^{-1} \\
0.2 @ 0.22 \mathrm{mg} \mathrm{m}^{-2} \mathrm{~s}^{-1}\end{array}$ & Jensen et al., 1996 & $\begin{array}{l}\text { Alkali trap }=\mathrm{NaOH} \text {; used PP Systems } \\
\text { chamber as reference }\end{array}$ \\
\hline Average $=0.75 \pm 0.42$ & & \\
\hline
\end{tabular}




\begin{tabular}{lll}
\hline FT-NSS vs FT-SS & & \\
\hline FT-NSS/FT-SS & Reference & Comments \\
\hline 1.14 & Longdoz et al., 2001 & FT-NSS= LI-COR \\
0.93 & Norman et al., 1997 & FT-NSS = LI-COR \\
Average = 1.04 & & \\
\hline FT-NSS vs Micromet & & \\
\hline FT-NSS/micromet & Reference & Comments \\
\hline $0.82,1.06,1.0,0.9$ & Dugas, 1993 & $\begin{array}{l}\text { Bowen-Ratio system; 0.75-L chamber; } \\
\text { Fc }<0.057 \text { mg } \mathrm{m}^{-2} \mathrm{~s}^{-1} .\end{array}$ \\
1.0 & Norman et al. (1997) & $\begin{array}{l}\text { Eddy covariance was corrected for plant } \\
\text { contribution to Fc }\end{array}$ \\
1.04 & Rochette et al. (1997) & Eddy covariance system; Large variability \\
Average $=0.97 \pm 0.09$ & & \\
\hline
\end{tabular}

ear relationship between the two estimates with a slope of $0.91, r^{2}$ of 0.95 and standard error of 0.096 (Fig. 12-6). We computed the ratio of the NFT to FT estimate for each pair and assigned it to one of several groups, each representing a different range of flux intensity. The ratios averaged $0.938( \pm 0.341)$ over all groups. Group means were also $<1$ except for fluxes between 0.08 to $0.12 \mathrm{mg} \mathrm{m}^{-2}$ $\mathrm{s}^{-1}$ and reached their lowest value $(0.75)$ at about $0.2 \mathrm{mg} \mathrm{m}^{-2} \mathrm{~s}^{-1}$. In a separate field comparison Norman et al. (1997) also reported smaller $F_{\mathrm{c}}$ estimates from NFT compared with FT chamber systems, but they found the difference to be 30 to $50 \%$ instead of the approximately $7 \%$ difference reported here. A $20 \%$ underestimation of $F_{\mathrm{c}}$ by NFT-NSS chambers compared with FT-NSS is consistent

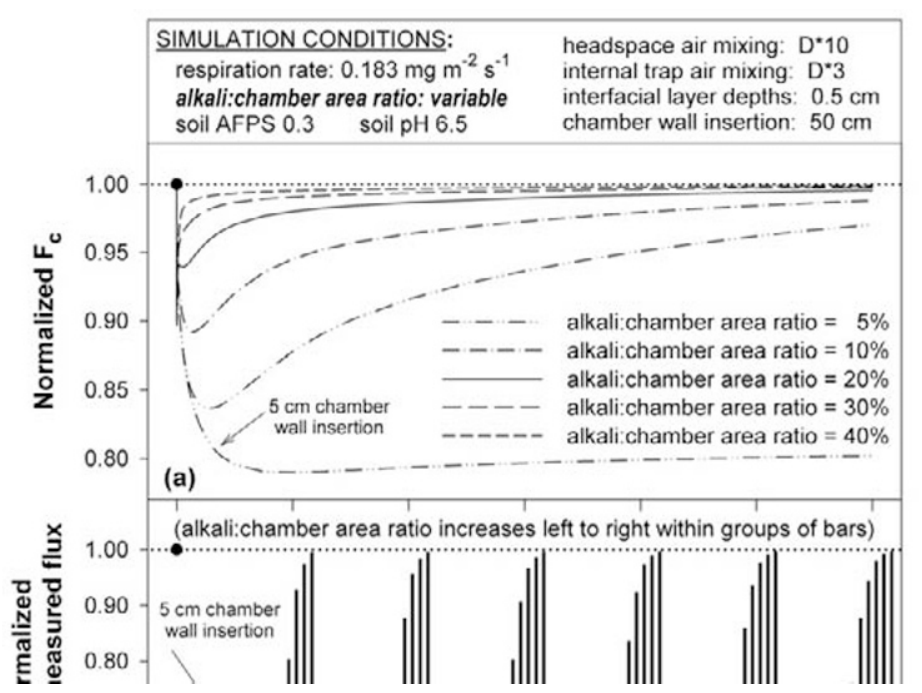

Fig. 12-6. Comparisons between flow-through (FT) and non-flow-through (NFT) non-steady-state chamber soil-surface $\mathrm{CO}_{2}$ flux measurements. 
with model predictions of differences between $F_{\mathrm{c}}$ estimates based on short and long deployment times (Healy et al., 1996).

Intercomparisons between chamber types should be interpreted with caution for several reasons. First, investigators rarely have the same experience and expertise with all techniques being compared, so the different measurement systems may not be equally optimized; e.g., Norman et al. (1997) reported intercomparison results using NFT-NSS chambers that were not optimized for $\mathrm{CO}_{2}$ flux measurements. Second, the various chamber types don't perform equally well under all conditions. In fact, each type is best adapted for use in specific situations, so the conditions of the comparison may bias the results. For example, NFT-SS chambers deployments of only a few hours are more likely to be significantly influenced by their initial non-steady-state condition than more typical 12or 24-h deployments. Thus, they have an inherent disadvantage in comparisons across short deployment periods (Rochette et al., 1992).

\section{Spatial and Temporal Integration}

When appropriate precautions are observed, chambers provide reliable estimates of soil-surface $\mathrm{CO}_{2}$ fluxes; however, most chambers are small and are deployed for short periods of time, so those estimates must often be integrated over space and time to satisfy the research objectives. Soil respiration varies in both time and space in response to changes in soil heterotrophic activity and rootrhizosphere respiration. Soil heterotrophic decomposition processes are regulated by several factors, including the quantity and quality of soil organic substrates (soil organic matter, litterfall, crop residues, organic amendments, etc.) and soil disturbance (tillage, freeze-thaw, rewetting, etc.), while root-rhizosphere respiration depends on root biomass, phenology, soil fertility, etc. (Hanson et al., 2000). Moreover, both respiration activities are modulated by soil physical factors such as temperature, water content and permeability to water and gases, all of which vary to a great extent in both space and time in most ecosystems. Thus, spatial and temporal integration of instantaneous $F_{\mathrm{c}}$ values from point sources is a challenge for chamber users. In this section, we briefly review how the selection of an adequate chamber type, chamber design and sampling methodology can minimize the resulting errors when spatial and temporal integration of $F_{c}$ are estimated from individual chamber measurements.

\section{Spatial Integration of $\boldsymbol{F}_{\mathrm{c}}$ Measurements}

Because chamber measurements are time consuming and labor intensive, sampling schemes must be chosen to obtain the information required by the research objectives using a minimum number of measurements. Selecting the appropriate chamber geometry and sampling strategy are key factors for achieving this goal.

Chamber geometry can address spatial variability problems at small scales $(<1 \mathrm{~m})$. For example, in a row crop, root growth patterns and soil compaction in the inter-row spaces often result in an $F_{\mathrm{c}}$ gradient perpendicular to the plant rows (Rochette et al., 1991). If the research objectives require describing that gradient, 
long and narrow rectangular chambers are most appropriate. The chamber width (perpendicular to the row) should be much smaller (three times or more) than the width of the inter-row space, while the dimension parallel to the row should be as long as possible to integrate random variability. If description of the inter-row gradient in $F_{\mathrm{c}}$ is not required, then chambers covering the whole inter-row are most efficient. Such chambers could be square and deployed from one plant row to the next, or long (equal to the inter-row width) and narrow (equal to the distance between plants) and deployed centered on the row. In natural ecosystems, random plant location, roots and rocks are additional factors that dictate chamber geometry; however, the chamber should always cover an area as large as practical while providing information at the smallest scale for which it is needed. Using a chamber with geometry that is not optimized to the research objectives and terrain characteristics results in wasted resources and a loss of accuracy in spatial integration. Selecting the most appropriate chamber characteristics can make the difference between a successful experiment and a frustrating experience.

Choosing a sampling strategy should be guided by the need to provide affordable estimates of $F_{c}$ at the scale of interest. This scale can vary from small agronomic plots $\left(\mathrm{a}\right.$ few $\mathrm{m}^{2}$ ) to agricultural fields or natural ecosystems (a few ha). Soil is not a homogeneous medium and most ecosystems can be viewed as a mosaic of $\mathrm{CO}_{2}$ sources of various intensities. A sampling strategy that accounts for the proportional contribution of these different sources to total ecosystem $F_{\mathrm{c}}$ requires knowledge of the spatial patterns of soil respiration. Such knowledge can be obtained from an exploratory survey prior to the experiment or by analysis of the spatial variation in factors that regulate respiration. Rochette et al. (1991) showed that spatial patterns of soil respiration vary considerably during the growing season, even in an ecosystem as homogeneous as a wheat field, so the most appropriate sampling strategy also may change as a function of time.

Spatial variation in $F_{\mathrm{c}}$ occurs at scales ranging from centimeter to kilometer and may be random or spatially organized. The most appropriate sampling strategy in ecosystems where $F_{\mathrm{c}}$ varies randomly is to perform a sufficient number of randomly distributed chamber measurements to yield an estimate of $F_{\mathrm{c}}$ that has an acceptable level of confidence. In small non-vegetated plots one large chamber may provide a valid estimate of $F_{c}$, but in complex ecosystems a large number of measurements may be required to reduce the coefficient of variation below $20 \%$ (Rochette et al., 1991). When a large number of measurements is needed in a midsize ecosystem (<1 ha), 2-min deployments of FT-NSS chambers are probably most appropriate; however, it may be impossible to sample a large ecosystem within a reasonable interval using one FT-NSS chamber, so in this case simultaneous deployment of many NFT-SS or NFT-NSS chambers may represent a better option, if sufficient labor is available. In ecosystems where $F_{\mathrm{c}}$ variations are spatially organized (Davidson et al., 1998), a stratified sampling strategy should be used; i.e., the number of chambers per stratum is weighted according to the area ratio of each stratum to the entire ecosystem. Finally, spatial variability can sometimes be reduced prior to the experiment; e.g., in an experiment designed to characterize the effects of an organic addition (manure, crop residues, etc.), applying the exact dose inside the chamber may reduce spatial variability compared with deploying the chamber after a broadcast application (Rochette et al., 2000). 


\section{Temporal Integration of $\boldsymbol{F}_{\mathrm{c}}$ Measurements}

Soil respiration varies in time according to astronomical rhythms as well as to soil disturbance, rainfall, severe drought, and other sudden or unusual changes in substrate supply or environmental conditions (Grahammer et al., 1991; Akinremi et al., 1999). In the absence of such changes, daily minimum and maximum $F_{\mathrm{c}}$ are usually recorded in early morning and afternoon in response to variations in $T_{\mathrm{s}}$ (Davidson et al., 1998). Plant photosynthesis reinforces this cycle by increasing the supply of substrate for root-rhizosphere respiration during daytime. Changes in $T_{\mathrm{s}}$ also govern seasonal variation in $F_{\mathrm{c}}$, which is therefore maximal in mid-summer and much lower in early spring and late fall (Rochette \& Gregorich, 1998). Respiration can be assumed to be zero in frozen soils, but may continue below the frozen layer as evidenced by the observation that $F_{\mathrm{c}}$ is rarely zero during winter at northern latitudes (Sommerfeld et al., 1993). Daily $F_{\mathrm{c}}$ is often estimated from a single measurement made at the time of day when $F_{\mathrm{c}}$ is believed equal to its daily mean value - variously reported as early morning and evening (Akinremi et al., 1999) or mid-morning and late afternoon (Rochette et al., 1997; Davidson et al., 1998). Annual estimates can be obtained by linear interpolation between representative daily values estimated weekly or biweekly.

Superimposed on daily and seasonal cycles are short periods of rapid change in $F_{\mathrm{c}}$ that occur in response to disturbances of the soil physical environment. For example, a short-lived but intense burst in $F_{\mathrm{c}}$ often follows tillage, as soil $\mathrm{CO}_{2}$ escapes through the large pores that are created (Reicosky \& Lindstrom, 1993; Rochette \& Angers, 1999). High $\mathrm{CO}_{2}$ emissions also occur when soils are amended with large quantities of decomposable organic substrates (Rochette et al., 2000), or when dry soils are rewetted (Rochette et al., 1991). In contrast, $F_{\mathrm{c}}$ can be very small in saturated soils following heavy rainfall. Snowmelt can have a strong impact on soil $\mathrm{N}$ dynamics, and high $\mathrm{N}_{2} \mathrm{O}$ fluxes have been reported at spring thaw (Wagner-Riddle et al., 1997). Effects of snowmelt on $F_{\mathrm{c}}$ are not as clear but may be significant under certain conditions. These and other transient fluxes can induce significant bias when temporal integration is performed by linear interpolation between weekly or biweekly measurements. Such episodes should be documented with more frequent sampling and excluded from the determination of empirical relationships between $F_{\mathrm{c}}$ and $T_{\mathrm{s}}$ or $H_{\mathrm{s}}$.

Automated FT-SS (Rayment \& Jarvis, 1997; McGinn et al., 1998) and FTNSS (Loftfield et al., 1992) chambers provide detailed description of the temporal variability in $F_{\mathrm{c}}$; however, technical constraints associated with sharing the gas analyzer limit the number of chambers and their spatial distribution. A combination of automated and portable chamber systems is often needed to obtain adequate spatial and temporal resolution of $F_{\mathrm{c}}$. NFT-SS chambers also can provide valuable information regarding average ecosystem $F_{\mathrm{c}}$, especially when they are carefully calibrated against other chamber techniques (Jannssens \& Ceulemans, 1998).

\section{Modeling $\boldsymbol{F}_{\mathrm{c}}$}

Spatial and temporal integration also can be accomplished by modeling approaches, which have the advantage that monitoring temporal and spatial vari- 
ations in a few controlling variables is often easier than measuring $F_{\mathrm{c}}$; however, because soil respiration is the result of complex interactions between many biotic and abiotic factors, sophisticated mechanistic soil respiration models require more detailed information than is easily available at most research sites. Alternative simple descriptions of the dependence of $F_{\mathrm{c}}$ on $T_{\mathrm{s}}$ usually provide adequate integration capability, because $F_{\mathrm{c}}$ is so strongly governed by $T_{\mathrm{s}}$ in the absence of water stress (Rochette \& Gregorich, 1998; Davidson et al., 1998; Buchmann, 2000; Ahrens et al., 2000). Under limiting soil water content, $H_{\mathrm{s}}$ has a profound effect on the $F_{\mathrm{c}}-T_{\mathrm{s}}$ relationship (Linn \& Doran, 1984; Grahammer et al., 1991; Norman et al., 1992), which can be included in the model via a mathematical function modulating the effect of $T_{\mathrm{s}}$ (Davidson et al., 1998). Nevertheless, all such empirical models are site-specific (and sometimes year- or season-specific), because other soil and vegetation factors are embodied in the model coefficients (Lloyd \& Taylor, 1994; Palmer et al., 1996). To avoid bias, the model must use a $T_{\mathrm{s}}$ that is representative of the soil layer where respiration occurs $(<30 \mathrm{~cm})$ and must account for diurnal cycles of $F_{\mathrm{c}}$ and $T_{\mathrm{s}}$. Suitability of the model coefficients should be checked at regular intervals to account for changes in substrate availability, root-rhizosphere respiration, and other factors that are unlikely to remain constant during the growing season.

\section{CONCLUSIONS}

Nearly all measurements of $F_{\mathrm{c}}$ reported in the literature were obtained using chambers, which are likely to remain the method of choice in the foreseeable future. Alternative methods cause less soil and atmospheric perturbations but offer greater uncertainty and/or greater cost and technical complexity. Approaches based on Fick's first law of diffusion (Rolston, 1986) are plagued by imprecision in estimating soil gas diffusivity and by difficulty in determining the $\left[\mathrm{CO}_{2}\right]$ gradient, especially when respiration activity is non-uniformly distributed as a function of soil depth. Use of this approach is likely to remain limited to special situations such as winter emission through a physically uniform and biologically inactive snowpack. The eddy covariance technique can provide reliable monitoring of net ecosystem $\mathrm{CO}_{2}$ fluxes when used above large uniform surfaces (Rochette et al., 1995); however, it has limited value for estimating $F_{\mathrm{c}}$ in even simple ecosystems, because of uncertainty related to separating $\mathrm{CO}_{2}$ sources and sinks over the measured surface (Norman et al., 1992), of using air density correction terms that are often larger than $F_{c}$ and of the violation of assumptions such as horizontal homogeneity of the source area.

Chambers are, of course, also not exempt from methodological problems, and in this chapter we reviewed known sources of chamber-induced errors in $F_{\mathrm{c}}$ estimates. Despite the multiplicity and diversity of potential errors, however, we believe their overall impact on chamber-based $F_{\mathrm{c}}$ estimates will be minimal if the information summarized herein is used to select the chamber design best suited to the research objective and to establish the optimum protocol to be followed before, during, and after the measurement period. As soil respiration measurements become part of an increasing number of field studies, scientists from vari- 
ous backgrounds and often with limited knowledge of soil physics and agrometeorology will begin measuring $F_{\mathrm{c}}$ using chamber techniques. We hope that the theoretical considerations and practical recommendations given in this chapter will help them to ensure that their $F_{\mathrm{c}}$ estimates have the highest quality attainable.

\section{REFERENCES}

Ahrens, T., H. Lux, J. Melillo, P. Steudler, and F. Bowles. 2000. Interannual variability in soil respiration in an aggrading mixed hardwood stand at the Harvard Forest. In 11th Annual Harvard Forest Ecology Symp., Apr. 12, 2000, Petersham, MA. Harvard Forest, Petersham, MA. Http://harvardforest.fas.harvard.edu/publications/symposium/symp00.html.

Akinremi, O.O., S.M. McGinn, and H.D.J. McLean. 1999. Effects of soil temperature and moisture on soil respiration in barley and fallow plots. Can. J. Soil Sci. 79:5-13.

Ambus, P., and G.P. Robertson. 1998. Automated near-continuous measurement of carbon dioxide and nitrous oxide fluxes with a photoacoustic infra-red spectrometer and flow-through soil cover boxes. Soil Sci. Soc. Am. J. 62:394-400.

Anderson, J.P.E. 1982. Soil respiration. p. 831-853. In A.L. Page et al. (ed.) Methods of soil analysis. Part. 2. Chemical and microbiological properties. 2nd ed. ASA and SSSA. Madison, WI.

Anthony, W.H., G.L. Hutchinson, and G.P. Livingston. 1995. Chamber measurement of soil-atmosphere gas exchange: Linear vs. diffusion-based flux models. Soil Sci. Soc. Am. J. 59:1308-1310.

Bekku, Y., H. Koizumi, T. Nakadai, and H. Iwaki. 1995. Measurement of soil respiration using closed chamber method: An IRGA technique. Ecological Res. 10:369-373.

Bekku, Y., H. Koizumi, T. Nakadai, and H. Iwaki. 1997. Examination of four methods for measuring soil respiration. Appl. Soil Ecol. 5:247-254.

Bornemann, F. 1920. Kohlensaure und Pflanzenwachstum. Mitt. Dtsch. Landwirtsch.-Ges. 35:363.

Buchmann, N. 2000. Biotic and abiotic factors controlling soil respiration rates in Picea abies stands. Soil Biol. Biochem. 32:1625-1635.

Christensen, S. 1983. Nitrous oxide emission from the soil surface: Continuous measurement by gas chromatography. Soil Biol. Biochem. 15:481-483.

Coleman, D.C. 1973. Compartmental analysis of total soil respiration: An exploratory study. Oikos 24:361-366.

Coleman, D.C., and D.A. Crossley. 1996. Decomposition and nutrient cycling. p. 109-140. In Fundamentals of soil ecology. Associated Press, New York.

Conen, F., and K.A. Smith. 1998. A re-examination of closed flux chamber methods for the measurement of trace gas emissions from soils to the atmosphere. Eur. J. Soil Sci. 49:701-707.

Crill, P.M. 1991. Seasonal patterns of methane uptake and carbon dioxide release by a temperate woodland. Global Biogeochem. Cycles 5:319-334.

Cropper, W.L., K.C. Ewel, and J.W. Raich. 1985. The measurement of soil $\mathrm{CO}_{2}$ evolution in situ. Pedobiologia 28:35-40.

Davidson, E.A, E. Belk, and R.D. Boone. 1998. Soil water content and temperature as independent or confounding factors controlling soil respiration in a temperate mixed hardwood forest. Global Change Biol. 4:217-227.

Denmead, O.T. 1979. Chamber systems for measuring nitrous oxide emissions from soils in the field. Soil Sci. Soc. Am. J. 43:89-95.

Doran, J.W., and T.B. Parkin. 1994. Defining and assessing soil quality. p. 3-22. In J.W. Doran et al. (ed.) Defining soil quality for a sustainable environment. SSSA Spec. Publ. 35. SSSA, Madison, WI.

Douglas, L.A., and J.C.F Tedrow. 1959. Organic matter decomposition rates in arctic soils. Soil Sci. 88:305-312.

Dugas, W.A. 1993. Micrometeorological and chamber measurements of $\mathrm{CO}_{2}$ flux from bare soil. Agric. For. Meteorol. 67:115-128.

Edwards, N.T. 1974. A moving chamber design for measuring soil respiration rates. Oikos 25:97-101.

Edwards, N.T. 1982. The use of soda lime for measuring soil respiration rate in terrestrial ecosystems. Pedobiologia 23:321-330.

Ewel, K.C., W.P. Cropper, and H.L. Gholz. 1987. Soil $\mathrm{CO}_{2}$ evolution in Florida slash pine plantations: I. Changes through time. Can. J. For. Res. 17:325-329. 
Fang, C., and J.B. Moncrieff. 1996. An improved dynamic chamber technique for measuring $\mathrm{CO}_{2}$ efflux from the surface of the soil. Funct. Ecol. 10:297-305.

Fang, C., and J.B. Moncrieff. 1998. An open-top chamber technique for measuring soil respiration and the influence of pressure difference on $\mathrm{CO}_{2}$ flux measurements. Functional Ecol. 12:319-326.

Freijer, J.I., and W. Bouten. 1991. A comparison of field methods for measuring soil carbon dioxide evolution: Experiments and simulation. Plant Soil 135:133-142.

Glinski, J., and W. St_pniewski. 1985. Soil aeration and its role for plants. CRC Press, Boca Raton, FL.

Goulden, M.L., and P.M. Crill. 1997. Automated measurements of $\mathrm{CO}_{2}$ exchange at the moss surface of a black spruce forest. Tree Physiol. 17:537-542.

Grahammer, K, M.D. Jawson, and J. Skopp. 1991. Day and night soil respiration from a grassland. Soil Biol. Biochem. 23:77-81.

Greenwood, D.J. 1961. The effect of oxygen concentration on the decomposition of organic materials in soils. Plant Soil 14:360-376.

Grogan, P. 1998. $\mathrm{CO}_{2}$ flux measurement using soda-lime: Correction for water formed during $\mathrm{CO}_{2}$ absorption. Ecology 79:1467-1468.

Gupta, S.R., and J.S. Singh. 1977. Effect of alkali volume and absorption area on the measurement of soil respiration in a tropical sward. Pedobiologia 17:223-239.

Haber, W. 1958. Oekologische Untersuchungen der Bodenatmung. [Ecological analysis of soil respiration (review of methods)]. Flora 146:109-157.

Hanson, P.J., N.T. Edwards, C.T. Garten Jr., and J.A. Andrews. 2000. Separating root and soil microbial contributions to soil respiration: A review of methods and observations. Biogeochemistry 48:115-146.

Hanson, P.J., S.D. Wullschleger, S.A, Bohlman, and D.E. Todd. 1993. Seasonal and topographic patterns of forest floor $\mathrm{CO}_{2}$ efflux from an upland oak forest. Tree Physiol. 13:1-15.

Haynes, B.E., and S.T. Gower. 1995. Below-ground carbon allocation in unfertilised and fertilised red pine plantations in Northern Wisconsin. Tree Physiol. 15:317-325.

Healy, R.W., R.G. Striegl, T.F. Russell, G.L. Hutchinson, and G.P. Livingston. 1996. Numerical evaluation of static-chamber measurements of soil-atmosphere gas exchange: Identification of physical processes. Soil Sci. Soc. Am. J. 60:740-747.

Holland, E.A., G.P. Robertson, J. Greenburg, P. Groffman, R. Boone, and J. Gosz. 1999. Soil $\mathrm{CO}_{2}$, $\mathrm{N}_{2} \mathrm{O}$, and $\mathrm{CH}_{4}$ exchange. p. 185-201. In G.P. Roberston et al. (ed.) Standard soil methods for long-term ecological research. Oxford Univ. Press, New York.

Humfeld, H. 1930. A method for measuring carbon dioxide evolution from soil. Soil Sci. 30:1-9.

Hutchinson, G.L., and G.P. Livingston. 2001. vents and seals in non-steady-state chambers for measuring gas exchange between soil and the atmosphere. Eur. J. Soil Sci. 52:675-682.

Hutchinson, G.L., and G.P. Livingston. 2002. Soil-atmosphere gas exchange. p. 1159-1182. In J.H. Dane and G.C. Topp (ed.) Methods of soil analysis. Part 4. SSSA Book Ser. 5. SSSA, Madison, WI.

Hutchinson, G.L., G.P. Livingston, R.W. Healy, and R.G. Striegl. 2000. Chamber measurement of surface-atmosphere trace gas exchange: dependence on soil, interfacial layer, and source/sink properties. J. Geophys. Res. 105:8865-8876.

Hutchinson, G.L., and A.R. Mosier. 1981. Improved soil cover method for field measurement of nitrous oxide fluxes. Soil Sci. Soc. Am. J. 45:311-316.

Hutchinson, G.L., and P. Rochette. 2003. Non-flow-through steady-state chambers for measuring soil respiration: Numerical evaluation of their performance. Soil Sci. Soc. Am. J. 67:166-180.

Iritz, Z., A. Lindroth, and A. Gärdenäs. 1997. Open ventilated chamber system for measurements of $\mathrm{H}_{2} \mathrm{O}$ and $\mathrm{CO}_{2}$ fluxes from the soil surface. Soil Technol. 10:169-184.

Janssens, I.A, and R. Ceulemans. 1998. Spatial variability in forest soil $\mathrm{CO}_{2}$ efflux assessed with a calibrated soda lime technique. Ecol. Lett. 1:95-98.

Janssens, I.A., A.S. Kowalski, B. Longdoz, and R. Ceulemans. 2000. Assessing forest soil $\mathrm{CO}_{2}$ efflux: An in situ comparison of four techniques. Tree Physiol. 20:23-32.

Jensen, L.S., T. Mueller, K.R. Tate, D.J. Ross, J. Magid, and N.E. Nielsen. 1996. Soil-surface $\mathrm{CO}_{2}$ flux as an index of soil respiration in situ: A comparison of two chamber methods. Soil Biol. Biochem. 28:1297-1306.

Kanemasu, E.T., W.L. Powers, and J.W. Sij. 1974. Field chamber measurements of $\mathrm{CO}_{2}$ flux from soil surface. Soil Sci. 118:233-237.

Kessavalou A., A.R. Mosier, J.W. Doran, R.A. Drijber, D.J. Lyon, and O. Heinemeyer. 1998. Fluxes of $\mathrm{CO}_{2}, \mathrm{~N}_{2} \mathrm{O}$ and $\mathrm{CH}_{4}$ in grass sod and winter wheat-fallow tillage management. J. Environ. Qual. 27:1094-1104. 
Kilham, K. 1994. The ecology of soil nutrient cycling. p. 89-108. In Soil ecology. Cambridge University Press, Cambridge, NY.

Kimball, B.A. 1983. Canopy gas exchange: Gas exchange with soil. p. 215-226. In H.M. Taylor et al. (ed.) Limitations to efficient water use in crop production. ASA, CSSA, SSSA Spec. Publ. Madison, WI.

Kimball, B.A., and E.R. Lemon. 1971. Air turbulence effects upon soil gas exchange. Soil Sci. Soc. Am. Proc. 35:16-21.

Kirita, H. 1971. Re-examination of the absorption method of measuring soil respiration under field conditions: III. Combined effect of the covered ground area and the surface area of $\mathrm{KOH}$ solution on $\mathrm{CO}_{2}$ absorption rates. Jap. J. Ecol. 21:43-47.

Kirita, H., and K. Hozumi.1966. Re-examination of the absorption method of measuring soil respiration under field conditions: I. Effect of the amount of $\mathrm{KOH}$ on observed values. Physiol. Ecol. $14: 23-31$.

Koizumi, H., T. Nakadai, Y. Usami, M. Satoh, M. Shiyomi, and T. Oikawa. 1991. Effect of $\mathrm{CO}_{2}$ concentration on microbial respiration in soil. Ecol. Res. 6:227-232.

Kucera, C.L., and D.R. Kirkham. 1971. Soil respiration studies in tallgrass prairie in Missouri. Ecology 52:912-915.

Le Dantec, V., D. Epron, and E. Dufrêne. 1999. Soil $\mathrm{CO}_{2}$ efflux in a beech forest: Comparison of two closed dynamic systems. Plant Soil 214:125-132.

Lieth, H., and R. Ouellette. 1962. Studies of the vegetation of the Gaspé peninsula: II. The soil respiration of some plant communities. Can. J. Bot. 40:127-140.

Linn, D.M., and J.W. Doran. 1984. Effect of water-filled pore space on carbon dioxide and nitrous oxide production in tilled and non-tilled soils. Soil Sci. Soc. Am. J. 48:1267-1272.

Livingston, G.P., and G.L. Hutchinson. 1995. Enclosure-based measurement of trace gas exchange: Applications and sources of error. p. 14-51. In P.A. Matson and R.C. Harriss (ed.) Biogenic trace gases: Measuring emissions from soil and water. Blackwell Science Ltd., Oxford, England.

Lloyd, J., and J.A. Taylor. 1994. On the temperature dependence of soil respiration. Ecology $8: 315-323$.

Lockyer, D.R. 1984. A system for the measurement in the field of losses of ammonia through volatilization. J. Sci. Food Agric. 35:837-848.

Lodge, J.P. 1988. Methods of air sampling and analysis. 3rd ed. Lewis Publ., CRC Press, Boca Raton, FL.

Loftfield, N.S., R. Brumme, and F. Beese. 1992. Automated monitoring of nitrous oxide and carbon dioxide flux from forest soils. Soil Sci. Soc. Am. J. 56:1147-1150.

Longdoz, B., M. Yernaux, and M. Aubinet. 2001. Soil $\mathrm{CO}_{2}$ efflux measurements in a mixed forest: Impact of chamber disturbances, spatial variability and seasonal evolution. Global Change Biol. 6:907-917.

Loubet, B., P. Cellier, D. Flura, and S. Génermont. 1999. An evaluation of the wind tunnel technique for estimating ammonia volatilisation from land: Part 1 . Analysis and improvement of accuracy. J. Agric. Eng. Res. 72:71-81.

Lundegårdh, H. 1921. Ecological studies in the assimilation of certain forest plants and shore plants. Sven. Bot. Tidskr. 15:46-94.

Lundegårdh, H. 1926. Carbon dioxide evolution of soil and crop growth. Soil Sci. 23:417-454.

MacFadyen, A. 1973. Inhibitory effects of $\mathrm{CO}_{2}$ on microbial activity in soil. Pedobiologia 13:140-149.

Makarov, B.N. 1959. A simple method of determining soil respiration. Pochvovedeniye 9:119-122.

Matthias, A.D., A.M. Blackmer, and J.M. Bremner. 1980. A simple chamber technique for field measurement of emissions of nitrous oxide from soils. J. Environ. Qual. 9:251-256.

Matthias, A.D., and A.R. Peralta-Hernández. 1998. Modelling temperatures in soil under an opaque cylindrical enclosure. Agric. Forest Meteorol. 90:27-38.

Matthias, A.D., D.N. Yarger, and R.S. Weinbeck. 1978. A numerical evaluation of chamber methods for determining gas fluxes. Geophys. Res. Lett. 5:765-768.

McGinn, S.M., O.O. Akinremi, H.D.J. McLean, and B.H. Ellert. 1998. An automated chamber system for measuring soil respiration. Can. J. Soil Sci. 78:573-579.

Medina, E., and M. Zelwer. 1972. Soil respiration in tropical plant communities. p. 245-269. In O.M. Golley and F.B. Golley (ed.) Proc. of the New Delhi Symposium on Tropical Ecology with an Emphasis on Organic Productivity, Jan. 1971, New Delhi, India. Compiled by the Univ. of Georgia, Athens.

Mina, V.N. 1962. Comparison of methods for determining the intensity of soil respiration. Sov. Soil Sci. 10:1188-1192. 
Minderman, G., and J.C. Vulto. 1973. Comparison of techniques for the measurement of carbon dioxide evolution from soil. Pedobiologia 13:73-80.

Morén, A.-S., and A. Lindroth. 1999. Flux measurements of water vapour and carbon dioxide fluxes: Chamber system and climatic monitoring by an automated station. Rep. 4. Dep. for Production Ecology. Fac. of Forestry, SLU, Uppsala, Sweden.

Mosier, A.R., and G.L. Hutchinson. 1981. Nitrous oxide emissions from cropped fields. J. Environ. Qual. 10:169-173.

Nakadai, T., H. Koizumi, Y. Usami, M. Satoh, and T. Oikawa. 1993. Examination of the methods for measuring soil respiration in cultivated land: Effect of carbon dioxide concentration on soil respiration. Ecol. Res. 8:65-71.

Naganawa, T., and K. Kyuma. 1991. Concentration dependence of $\mathrm{CO}_{2}$ evolution from soil in chamber with low $\mathrm{CO}_{2}$ concentration $(<2000 \mathrm{ppm})$ and $\mathrm{CO}_{2}$ diffusion/sorption modelling in soil. Soil Sci. Plant Nutr. 37:381-386.

Nakayama, F.S. 1990. Soil respiration. Remote Sens. Rev. 5:311-321.

Nay, S.M., K.G. Mattson, and B.T. Bormann. 1994. Biases of chamber methods for measuring soil $\mathrm{CO}_{2}$ efflux demonstrated with a laboratory apparatus. Ecology 75:2460-2463.

Norman, J.M., R. Garcia, and S.B. Verma. 1992. Soil surface $\mathrm{CO}_{2}$ fluxes and the carbon budget of a grassland. J. Geophys. Res. 97:18 845-18 853.

Norman, J.M., C.J. Kucharik, S.T. Gower, D.D. Baldocchi, P.M. Crill, M.B. Rayment, K. Savage, and R.G. Striegl. 1997. A comparison of six methods for measuring soil-surface carbon dioxide fluxes. J. Geophys. Res. 102:28 771-28 777.

Palmer-Winkler, J., R.S. Cherry, and W.L. Schlesinger. 1996. The Q10 relationship of microbial respiration in a temperate forest soil. Soil Biol. Biochem. 28:1067-1072.

Parkinson, D. 1981. An improved method for measuring soil respiration in the field. J. Appl. Ecol. 18:221-228.

Parr, J.F., and H.W. Reuszer. 1959. Organic matter decomposition as influenced by oxygen level and method of application to soil. Soil Sci. Soc. Am. Proc. 23:214-216.

Pedersen, A.R. 2000. Estimating the nitrous oxide emission rate from the soil surface by means of a diffusion model. Scand. J. Stat. 27:385-403.

Pedersen, A.R., S.O. Petersen, and F.P. Vinther. 2001. Stochastic diffusion model for estimating trace gas emissions with static chambers. Soil Sci. Soc. Am. J. 65:49-58.

Raich, J.W., R.D. Bowden, and P.A. Steudler. 1990. Comparison of two static chamber techniques for determining carbon dioxide efflux from forest soils. Soil Sci. Soc. Am. J. 54:1754-1757.

Rayment, M.B. 2000. Closed chamber systems underestimate soil $\mathrm{CO}_{2}$ efflux. Europ. J. Soil Sci. 51:107-110.

Rayment, M.B., and P.G. Jarvis. 1997. An improved open chamber system for measuring soil $\mathrm{CO}_{2}$ effluxes in the field. J. Geophys. Res. 102:28 779-28 784.

Reicosky, D.C., W.A., Dugas, and H.A. Torbert. 1997. Tillage-induced soil carbon dioxide loss from different cropping systems. Soil Till. Res. 41:105-118.

Reicosky, D.C., and M. J. Lindstrom. 1993. Fall tillage method: Effect on short-term $\mathrm{CO}_{2}$ fluxes from soil. Agron. J. 85:1237-1243.

Reiners, W.A. 1968. Carbon dioxide evolution from the floor of three Minnesota forests. Ecology 49:471-483.

Rochette, P., and D.A. Angers. 1999. Soil-surface $\mathrm{CO}_{2}$ fluxes induced by spring, summer and fall moldboard plowing in a sandy loam. Soil Sci. Soc. Am. J. 63:621-628.

Rochette, P., D.A. Angers, and D. Côté. 2000. Soil carbon and nitrogen dynamics following application of pig slurry for the 19th consecutive year: I. Microbial biomass carbon and $\mathrm{CO}_{2}$ fluxes. Soil Sci. Soc. Am. J. 64:1389-1395.

Rochette, P., and N. Bertrand. 2003. Soil air sample storage and handling using polypropylene syringes and glass vials. Can. J. Soil Sci. 83:631-637.

Rochette, P., M.H. Chantigny, D.A. Angers, N. Bertrand, and D. Côté. 2001. Ammonia volatilisation and soil nitrogen dynamics following fall application of pig slurry on canola crop residues. Can. J. Soil Sci. 81:515-523.

Rochette, P. R.L. Desjardins, and E. Pattey. 1991. Spatial and temporal variability of soil respiration in agricultural fields. Can. J. Soil Sci. 71:189-196.

Rochette, P., R.L. Desjardins, E. Pattey, and R. Lessard. 1995. Crop net carbon dioxide exchange rate and radiation use efficiency in soybean. Agron. J. 87:22-28.

Rochette, P., B. Ellert, E.G. Gregorich, R.L. Desjardins, E. Pattey, R. Lessard, and B.G. Johnson. 1997. Description of a dynamic closed chamber for measuring soil respiration and its comparison with other techniques. Can. J. Soil Sci. 77:195-203. 
Rochette, P., and E.G. Gregorich. 1998. Dynamics of soil microbial biomass C, soluble organic C and $\mathrm{CO}_{2}$ evolution after three years of manure application. Can. J. Soil. Sci. 78:283-290.

Rochette, P., E.G. Gregorich, and R.L. Desjardins. 1992. Comparison of static and dynamic closed chambers for measurement of soil respiration under field conditions. Can. J. Soil Sci. 72:605-609.

Rolston, D.E. 1986. Gas flux. p.1103-1119. In A. Klute (ed.) Methods of soil analysis. Part 1. Physical and mineralogical methods. 2nd ed. SSSA, Madison, WI.

Schwartzkopf, S.H. 1978. An open chamber technique for the measurement of the carbon dioxide evolution from soils. Ecology 59:1062-1068.

Scott, A., I. Crichton, and B.C. Ball. 1999. Long-term monitoring of soil gas fluxes with closed chambers using automated and manual systems. J. Environ. Qual. 28:1637-1643.

Sharkov, I.N. 1984. Determination of the rate of soil $\mathrm{CO}_{2}$ production by the absorption method. Sov. Soil Sci. 16:102-111.

Singh, J.S., and S.R. Gupta. 1977. Plant decomposition and soil respiration in terrestrial ecosystems. Bot. Rev. 43:449-528.

Sommerfeld, R.A., A.R. Mosier, and R.C. Musselman. 1993. $\mathrm{CO}_{2}, \mathrm{CH}_{4}$ and $\mathrm{N}_{2} \mathrm{O}$ flux through a Wyoming snowpack and implications for global budgets. Nature 361:140-142.

Stotzky, G. 1965. Microbial respiration. p. 1550-1572. In C.A. Black et al. (ed.) Methods of soil analysis. Part 2. ASA, CSSA, and SSSA, Madison, WI.

Striegl, R.G., T.A. McConnaughey, D.C. Thorstenson, E.P. Weeks, and J.C. Woodward. 1992. Consumption of atmospheric methane by desert soils. Nature 357:145-147.

Suarez, D.L. 1999. Impact of agriculture on $\mathrm{CO}_{2}$ fluxes as affected by changes in inorganic carbon. p. 257-272. In R. Lal et al. (ed.) Global climate change and pedogenic carbonates. CRC Press, Boca Raton, FL.

Van Cleve, K. P.L. Coyne, E. Goodwin, C. Johnson, and M. Kelley. 1979. A comparison of four methods for measuring respiration in organic material. Soil Biol. Biochem. 11:237-246.

Wagner-Riddle, C., G.W. Thurtell, G.K. Kid, E.G. Beauchamp, and R. Sweetman. 1997. Estimates of nitrous oxide emissions from agricultural fields over 28 months. Can. J. Soil Sci. 77:135-144.

Wallis, G.W., and S.A. Wilde. 1957. Rapid method for determination of carbon dioxide evolved from forest soils. Ecology 38:359-361.

Welles, J.M., and D.K. McDermitt. 2005. Measuring carbon dioxide in the atmosphere. p. 267-300. In J.L. Hatfield and J.M. Baker (eds.) Micrometeorology in agricultural systems. Agron. Monogr. 47. ASA, CSSA, and SSSA, Madison, WI (this publication).

Widén B., and A. Lindroth. 2003. A calibration system for soil carbon dioxide-efflux measurement chambers: Description and application. Soil Sci. Soc. Am. J. 67:327-334.

Zibilske, L.M. 1994. Carbon mineralization. p. 836-864. In Methods of soil analyses. Part 2. Microbiological and biochemical properties. SSSA Book Ser. 5. SSSA. Madison, WI. 